\title{
MONEY AND MONETARY POLICY IN THE EUROZONE: AN EMPIRICAL ANALYSIS DURING CRISES
}

\author{
JONATHAN BENCHIMOL \\ Bank of Israel \\ and \\ $E A B C N$ \\ ANDRÉ FOURÇANS \\ ESSEC Business School \\ and \\ THEMA
}

This paper analyzes the role of money and monetary policy as well as the forecasting performance of New Keynesian dynamic stochastic general equilibrium models with and without separability between consumption and money. The study is conducted over three crisis periods in the Eurozone, namely, the ERM crisis, the dot-com crisis, and the global financial crisis (GFC). The results of successive Bayesian estimations demonstrate that during these crises, the nonseparable model generally provides better out-of-sample output forecasts than the baseline model. We also demonstrate that money shocks have some impact on output variations during crises, especially in the case of the GFC. Furthermore, the response of output to a money shock is more persistent during the GFC than during the other crises. The impact of monetary policy also changes during crises. Insofar as the GFC is concerned, this impact increases at the beginning of the crisis, but decreases sharply thereafter.

Keywords: Money, Monetary Policy, Dynamic Stochastic General Equilibrium, Crises

\section{INTRODUCTION}

Since the seminal paper of Smets and Wouters (2003), and even as far back as the development of the New Keynesian paradigm in the mid-1990s, traditional New Keynesian dynamic stochastic general equilibrium (DSGE) models have not given an explicit role to money, neither in the Eurozone nor in the United States. When money is explicitly taken into consideration, its impact is generally found to be negligible [Ireland (2003); Andrés et al. (2006, 2009); Barthélemy et al. (2011)]. Yet Benchimol and Fourçans (2012) find that when risk aversion is sufficiently 
high, money has an impact on output dynamics. Furthermore, Canova and Menz (2011) use a small-scale structural monetary business cycle model to find that output and inflation fluctuations are influenced by money.

Whatever the structures of these models, monetary policy is a central element and its impact on output and inflation - through interest rate adjustments - is well documented, for example, in Smets and Wouters (2007).

The roles of money and monetary policy may also change during crises. The global financial crisis (GFC) hints at these possible changes. The policy arena surrounding these questions is ripe with endless debates, notably with regard to monetary policy and its possible influence on output and inflation. Chadha et al. (2014) find that money conveys significant information to the central bank when there are shocks to credit supply, as may be the case during crises. Also, El-Shagi and Giesen (2013) analyze the consequences of the Federal Reserve's response to the financial crisis and find evidence of the substantial impact of money on U.S. prices. The role of money in the U.S. business cycle is also highlighted in El-Shagi et al. (2015).

Analyses conducted via New Keynesian DSGE models may be useful for clarifying these questions. To conduct this type of analysis, it is useful to assume nonseparable preferences between consumption and real money holdings in such a model, compare this model with one where consumption and real money holdings are assumed to be time-separable, and conduct empirical analyses that focus on crisis periods. This approach enables us to study the role of money and monetary policy, in order to determine explicitly whether their impact on output and inflation is affected during crises.

The impact of money and monetary policy may change for various reasons: for instance, changes in the transmission mechanism due to variations in banks' behavior; changes in money holding and consumption/investment behavior; changes in portfolio allocation between money and other assets; changes in expectations or risk evaluation; and more generally, increase in uncertainty, and so forth.

This paper seeks to understand the impact of money and monetary policy on the dynamics of the economy during crises, and the forecasting performance and abilities of two types of models.

In terms of meaningful statistical observations, crisis periods do not, in general, last very long. Hence, to capture the impact of short-run changes in the dynamics of the economy, there is a need to use sample periods as short as possible. Yet one also needs to obtain a sufficient number of observations to achieve statistically significant sample sizes.

To deal with these two types of questions - namely, bringing forth the role of money and monetary policy and taking into consideration the short sample constraint-our research strategy consists of comparing two types of microfounded New Keynesian models in a DSGE framework and testing them over periods short enough to capture the crisis effects, but long enough to be statistically meaningful. 
The first model is a standard one, the baseline model, where money is omitted from the utility function - that is, where time-separable preferences between households' consumption and real money holdings are assumed. In this model, money is also excluded from the monetary policy rule, as in the baseline model of Galí (2008). The second model incorporates money in two different ways. First, by assuming nonseparability between real money balances and consumption, money is explicitly included in the utility function. ${ }^{1}$ This nonseparability between consumption and real balances could be significant in the Eurozone, especially during crisis periods [Jones and Stracca (2006)]. Second, as the central bank minimizes its loss function, at least with respect to inflation, its optimization program implies that money enters the monetary policy rule automatically [Woodford (2003)].

We apply Bayesian techniques to estimate these two models. We use Eurozone data over periods that include three different crises, namely, the beginning of the 1990s when there were speculative currency attacks on the European exchange rate mechanism (ERM); the growth and bursting of the dot-com bubble at the beginning of the 2000s; and the global financial crisis (GFC) from 2007 through 2011.

We analyze the dynamics of both models by studying the variance decomposition of the variables with respect to structural shocks (our focus is on money and monetary policy shocks, but markup and technology shocks are also taken into consideration) over the three periods. We compare the forecasting performance of the models in each period, as well as the responses of output, flexible-price output, output gap, and inflation to the shocks (IRF). Focusing on each of these periods sheds light on the specific role of money and monetary policy in crisis situations. It also provides informative results regarding output and inflation dynamics during periods of uncertainty.

The analysis shows that, during crises, the impact of money on output and flexible-price output variances is stronger than usually found in the literature [Ireland (2004); Andrés et al. (2006, 2009)]. The response of output to a money shock also increases, especially during the peaks of the ERM crisis and the GFC. The persistence of the response of output and flexible-price output to a money shock is higher during the GFC than during the other crises. The impact of conventional monetary policy on output and inflation also changes during crises. More specifically, as far as the GFC is concerned, the impact of monetary policy on output and inflation constantly increases until the peak of the crisis (2008 Q3). It then decreases sharply over the next two quarters, and remains at a lower and stable level through 2011.

The response of flexible-price output to a money shock during the GFC is about as strong as the response of output itself, and in addition is significantly stronger and longer lasting than during the other crises. Yet a monetary policy shock appears to have no effect on flexible-price output for either of the crises.

Finally, our analysis demonstrates that during crises, a New Keynesian model with nonseparable preferences between consumption and money, and with money in the Taylor (1993) rule, leads to better out-of-sample output forecasts than a 
standard New Keynesian model—assuming separable preferences between consumption and money. This information can be a valuable input for the central bank in its decision-making process.

In Section 2, we discuss the data and empirical methodology. We analyze the ERM crisis in Section 3, the dot-com crisis in Section 4, and the GFC in Section 5. We compare the three crises in Section 6 and offer a conclusion in Section 7.

\section{DATA AND EMPIRICAL METHODOLOGY}

The two New Keynesian DSGE models used in this paper are presented in the Online Appendix. The baseline model is the well-known Gali (2008) model (Model 1). The nonseparable model (Model 2) is presented in Benchimol and Fourçans (2012).

\subsection{Data}

We use the same data set for both models of the Eurozone. $\hat{y}_{t}$ is the output per capita, measured as the difference between the log of the real GDP per capita and its linear trend; $\hat{\pi}_{t}$ is the inflation rate, measured as the yearly log difference of the GDP deflator from one quarter to the same quarter of the subsequent year; and $\hat{\imath}_{t}$ is the short-term (three-month) nominal interest rate. The latter two are linearly detrended. This data set is extracted from the (Euro) Area Wide Model database (AWM) of Fagan et al. (2001). $\widehat{\mathrm{mp}}_{t}$ is the real money balances per capita, measured as the difference between the real money per capita and its linear trend, where real money per capita is measured as the log difference between the money stock per capita and the GDP deflator. We choose the $M 3$ monetary aggregate from the Eurostat database. As in Andrés et al. (2006), Barthélemy et al. (2011), Benchimol and Fourçans (2012), and De Santis et al. (2013), M3 is used because it serves as the institutional definition of money in the Eurozone and plays a prominent role in the definition of monetary policy. ${ }^{2}$

$\hat{y}_{t}^{\mathrm{f}}$, the flexible-price output, and $\widehat{\mathrm{mp}}_{t}^{\mathrm{f}}$, the flexible-price real money balances, are entirely determined by structural shocks.

\subsection{Methodology}

Theoretically, only very small sample sizes (from one to a few years) are able to capture the changes in the values of parameters owing to short-run crises. Yet, to be reliable, statistical analyses necessitate a sufficient amount of observations. As far as we know, there is no specific statistical rule establishing the minimum number of observations necessary for reliable Bayesian tests. To deal with this issue, we follow Fernández-Villaverde and Rubio-Ramírez (2004) by choosing a sample size of 48 observations (quarterly data over 12 years). Indeed, Fernández-Villaverde and Rubio-Ramírez (2004) demonstrate that such a sample size is sufficient to obtain valid Bayesian estimations. Confidence in such small-sample-size tests is 
reinforced by the fact that several studies have shown that small-sample Bayesian estimates tend to outperform classical ones, even when evaluated by frequentist criteria [Geweke et al. (1997); Jacquier et al. (2002)].

The periods of interest are presumed to contain higher uncertainty than standard periods. We choose to study three crises, as indicated earlier, in the years between 1990 Q1 and 2011 Q1. For every quarter of each crisis period, we run a Bayesian estimation using the 48 observations before each respective quarter. This reestimation through rolling windows of data is fairly typical in forecasting studies, because it generates a panel of forecasts at various horizons that allow assessment of the average forecasting performance of a given model.

We calibrate both models (see Appendix A for parameters' description and Appendix B for detailed calibration) and estimate them using Bayesian techniques for every quarter (see Appendix $\mathrm{C}$ for posteriors). We also run simulations and DSGE forecasts for both models, for every quarter in each crisis period.

Our purpose in this paper is not to present all the results, a very cumbersome task indeed. Instead, from the estimates, we intend to draw the evolution of the variance decomposition of variables with respect to different shocks in the short and the long run. We also intend to compare the forecasting performance of the two models and compare the main IRFs over crises.

The estimates provide values of micro and macro parameters through time that affect the dynamics of the variables. Figures C.1-C.3 in Appendix C suggest that our results are stable over the various periods. These figures also suggest that structural deep parameters $(\theta, \alpha, \sigma, v)$ change without displaying any drift (see Appendix A for parameters description). During crisis periods, these changes appear to result from structural economic changes rather than statistical artifacts [Hurtado (2014)]. Furthermore, the Online Appendix shows that the standard deviations of the structural parameter posterior means over our crisis periods are significantly lower than those of the nonstructural and macro parameters.

For both models, the diagnosis concerning the numerical maximization of the posterior kernel indicates that the optimization procedure leads to a robust maximum for the posterior kernel. The convergence of the proposed distribution to the target distribution is thus satisfied for all estimates and all moments. ${ }^{3}$

Furthermore, well-identified structural parameters are key for valid inference. For both models, after each estimation, we use global sensitivity analysis (GSA) techniques to test identification for all parameters [Ratto (2008)]. Following Iskrev (2010), all parameters, structural and nonstructural, are well identified. ${ }^{4}$

The role of each shock can be analyzed via the successive estimates and simulations, leading to variance decompositions of variables with respect to the shocks [the markup shock $\left(\varepsilon_{t}^{p}\right)$, the technology shock $\left(\varepsilon_{t}^{a}\right)$, the monetary policy shock $\left(\varepsilon_{t}^{i}\right)$, and the money shock $\left(\varepsilon_{t}^{m}\right)$ for Model 2]. For reasons already explained, we center this analysis on money and monetary policy shocks.

After each estimate, we perform out-of-sample DSGE forecasts (each over four periods, that is, one year) to compare the forecasting performance of the two models. ${ }^{5}$ To conduct these forecasting exercises, we simulate our estimated models 
starting with a given state and analyze the trajectories of the forecast endogenous variables.

Finally, we analyze the responses of output, flexible-price output, output gap, and inflation to money and monetary policy shocks. To avoid an over-cumbersome paper, we do not present all the IRFs for each crisis. We select two key points for each crisis, and for both models when appropriate, and compare the IRFs at different key points.

This analysis is done using Metropolis-Hastings iterations on the basis of the posterior means of each estimated variable. Then we evaluate the forecasts with respect to the actual data. Finally, we compare the forecasts of the two models by calculating their respective root-mean-squared deviations (RMSD). After calculating the sum of the absolute values of the corresponding RMSD over four out-of-sample forecasts, we compare these values between the two models. We also use the Giacomini and White (2006) test to compare the predictive abilities of both models.

The performance of our models is assessed via their forecasting abilities. We do not compare the models through their respective log marginal data density or posterior odds ratio, for several reasons. First, the difference between two log marginal data densities of two different models does not mean that we must disregard the model with the lowest log marginal data density. For instance, the latter model can still be used to perform forecasting under changing environments. Second, whatever the log marginal data density function, it may be argued that the model is designed to capture only certain characteristics of the data. ${ }^{6}$ Whether or not the marginal likelihood is a good measure for how well the model accounts for particular aspects of the data is an open question. Third, Models 1 and 2 do not have the same dimensions. Model 2 has more parameters (structural as well as nonstructural) and variables, and the Bayes factor discriminates against these. The Bayes factor penalizes the difference in the dimensionality of the parameter space, incarnating a strong preference for stingy modeling [Koop (2003); FernándezVillaverde and Rubio-Ramírez (2004); Del Negro et al. (2007)].

It can be argued that adding frictions to models may improve the in-sample fit [Bekiros and Paccagnini (2015); Villa (in press)]. However, when two different models that share neither the same historical variables (time series used for estimation) nor the same household's preferences are compared, this view is not applicable. Model 1 contains three historical variables (output, inflation, and interest rate), whereas Model 2 contains four historical variables (output, inflation, interest rate, and money) and a different household utility function. Hence, a comparison of the two models through their in-sample fits is not relevant in our case.

\section{EUROPEAN EXCHANGE RATE MECHANISM CRISIS}

The first period under scrutiny includes the European exchange rate mechanism (ERM) crisis of 1992. The peak of the crisis is characterized by the so-called Black 

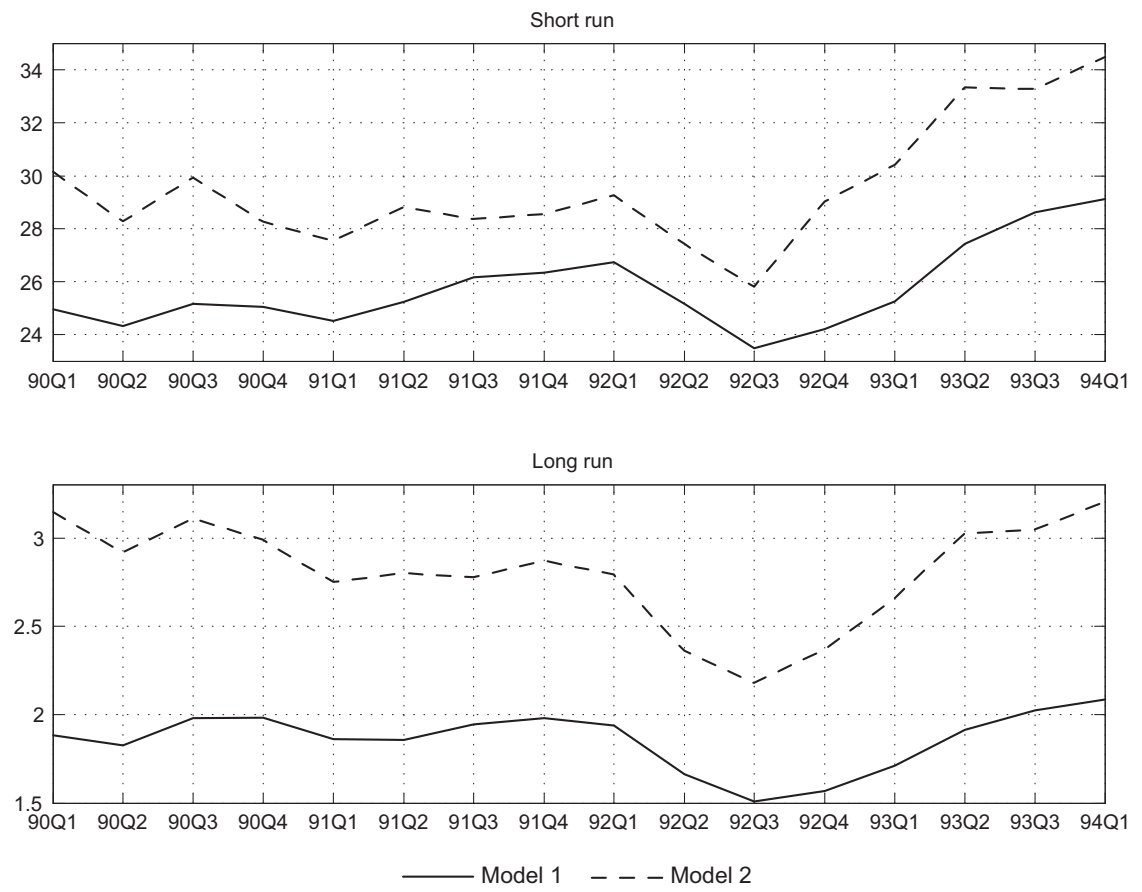

FIGURE 1. Variance decompositions of output with respect to the monetary policy shock (in percent) in Models 1 and 2.

Wednesday. This refers to the events of Wednesday, September 16, 1992, when the British government withdrew the pound sterling from the European ERM.

The period of analysis is from 1990 Q1 through 1994 Q1. Other crises also occurred during this period, such as the oil crisis following the first Gulf war ${ }^{7}$ from 1990 Q2 through 1991 Q2; the Russian crisis ${ }^{8}$ from 1992 Q2 through 1992 Q4; and the French real estate crisis ${ }^{9}$ from 1992 through 1996. In addition to the ERM crisis, these episodes also affected the Eurozone.

\subsection{Variance Decomposition}

For each Bayesian estimate of each model, we compute the short-run (conditional to the first period) and long-run (unconditional) variance decomposition of the variables with respect to the shocks.

The impact of money (Model 2) on output in the short run is relatively small (between $3 \%$ and $6 \%$ depending on the quarter). The impact in the long run is even smaller (between $0.5 \%$ and $1.1 \%$ ), and follows the same pattern through time.

The monetary policy shock plays a significant role in output fluctuations in the short run (Figure 1). It explains just below $30 \%$ of the output variance before 

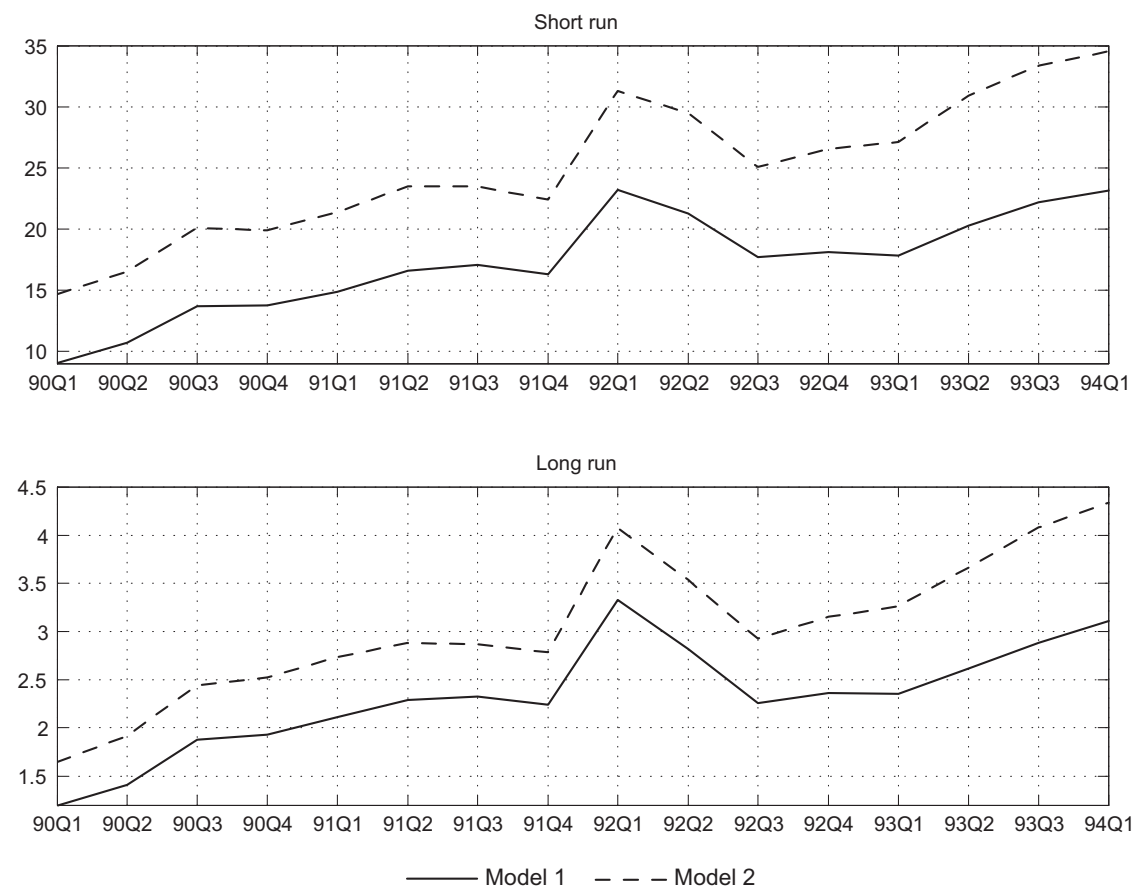

FIGURE 2. Variance decompositions of inflation with respect to the monetary policy shock (in percent) in Models 1 and 2.

1992 Q3 for Model 2, and the percentage increases quickly from this period. The long-run impact is much smaller (between $2 \%$ and $3 \%$ ).

All in all, output variability is mainly explained by the monetary policy shock (around 30\%) and the technology shock (around 60\%) in the short run for both models. The technology shock explains most of the variance in the long run (around 87\%) for both models. The markup shock has a negligible role on output in both the short and long run.

Money also plays a small role in explaining flexible-price output variations in the short run. The dynamics of these impacts follows a path similar to that of current output. The long-run impact of money on flexible-price output remains small.

Regardless of the model, the monetary policy shock has no impact on flexible-price output dynamics in either the short or long run. Flexible-price output is essentially explained by the technology shock in both runs (around $90 \%$ ) for both models.

The variance decomposition of inflation shows that the money shock has a very small role to play, be it in the short or long run (less than 2\%). As Figure 2 demonstrates, the monetary policy shock has a significant impact on inflation dynamics in the short run, but a very small one in the long run. The markup shock 


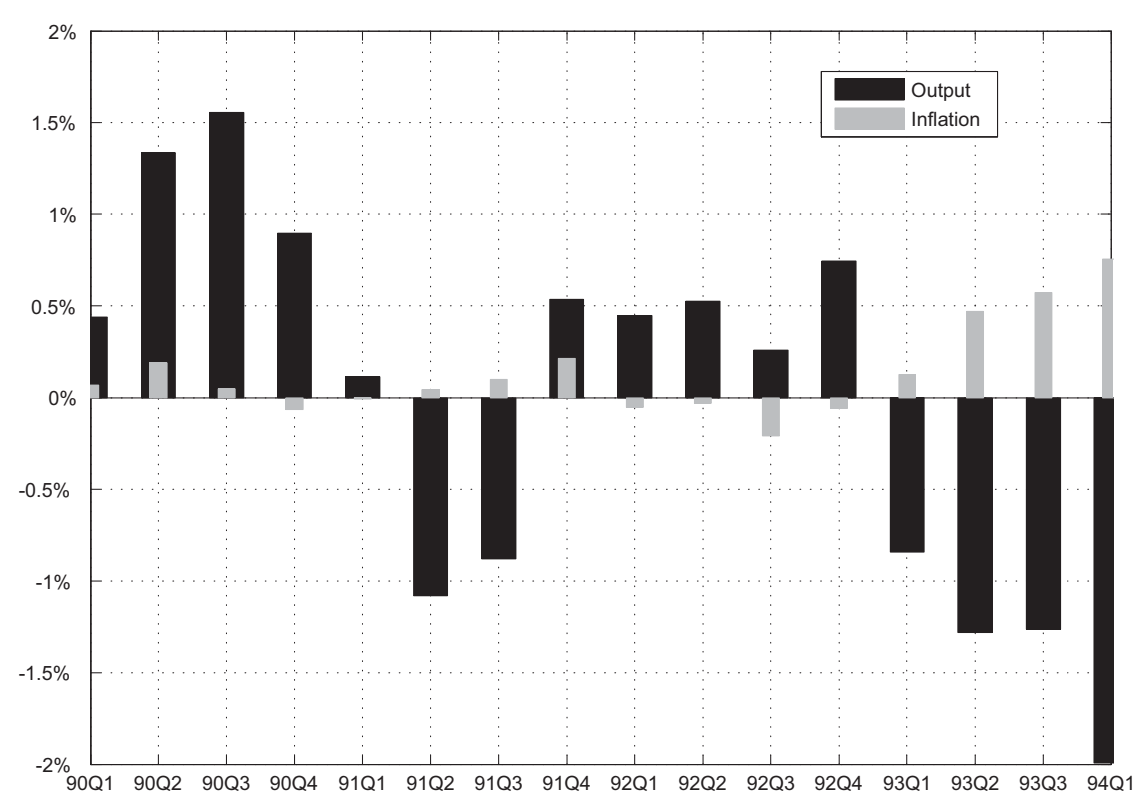

FIGURE 3. Comparison of output and inflation DSGE forecast errors. Model 2 is better when the bar is positive; Model 1 is better otherwise.

is important as well (around 80\%) in the short run and dominates the process in the long run (around 96\%) for both models.

Figures 1 and 2 indicate that the short-run impact of monetary policy on output remains relatively constant, whereas its impact on inflation increases from the beginning of the period until the peak of 1992 Q3. It increases in both cases after 1992 Q3 and the ERM crisis, whatever the model used.

However, the role of monetary policy appears to be greater in Model 2, with stronger impacts in the short than in the long run. ${ }^{10}$

\subsection{Forecasting Performance}

As mentioned previously, from each Bayesian estimates, we simulate the out-ofsample forecasts of output and inflation over the next four periods (one year) and compare these values with the historical values. This enables us to compute the RMSD of each period for each model. A negative number (negative bar) implies that the RMSD of the nonseparable model is higher than that of the baseline model. In such cases, the forecasting performance of Model 1 is better than that of Model 2. To further compare the forecasting performance of output, we also use the Giacomini and White (2006) tests of equal predictive ability.

Figure 3 shows that Model 2 has better predictive power for output dynamics than Model 1 when speculative attacks on currencies occurred between 1991 
Q4 and 1992 Q4. It is also the case in 1990, when other crisis events impacted the Eurozone (essentially, the oil crisis following the Gulf War). This result is confirmed by pairwise Giacomini and White (2006) tests of equal conditional and unconditional predictive ability of output over the period. Equal predictive ability of Models 1 and 2 is rejected and Model 2 outperforms Model 1 with a $p$-value of 0.001 (for conditional and unconditional predictive ability tests).

In terms of inflation, Figure 3 shows that the predictive power of the two models is quite similar, except after the ERM crisis, where Model 2 dominates Model 1. Also, Giacomini and White (2006) tests of equal predictive ability of inflation are not rejected (at least at $10 \%$ ).

\subsection{Interpretation}

The preceding analysis suggests that money has a small impact on output, even though this impact appears to be stronger than what Ireland (2004) and Andrés et al. (2006) found.

The transmission mechanism of shocks follows a complex process in our models. Such complexity is manageable when the impact of the money shock is studied; an analysis of the macro-parameters is, in this case, sufficient to interpret changes in the transmission process. ${ }^{11}$ It is more complicated to interpret changes in the transmission mechanism of a monetary policy shock. An analysis of the values of the macro-parameters alone is not sufficient. The monetary policy shock $\left(\varepsilon_{t}^{i}\right)$ enters the model through the Taylor rule; furthermore, there is no macro-coefficient enabling a direct study of its impact. Therefore, it is hard to analyze the changes in the impact of such a shock, other than through the variance decomposition results.

Figure 1 indicates that in 1992 Q3, at the peak of the ERM crisis, the impact of monetary policy on output reaches its lowest level. This may be due to the conduct of monetary policy, which in that period was more focused on limiting exchange rate variations than on stabilizing output.

The RMSD errors comparison (Figure 3) highlights two different periods, namely, from 1990 Q2 through 1991 Q1 and from 1991 Q4 through 1992 Q4, whereby Model 2 has better predictive abilities than Model 1 .

\section{DOT-COM CRISIS}

The bursting of the dot-com bubble in the Eurozone occurred approximately one quarter later (2000 Q3) than in the United States (2000 Q2). Our period of study is from 1999 Q1 through 2003 Q1. This enables us to analyze the peak of the bubble in the Eurozone (2000 Q2-Q3) and the period following the burst of the bubble.

\subsection{Variance Decomposition}

The impact of the money shock on output variance when the bubble was in process (between 2000 Q1 and Q4) is small in the short run (between 2\% and 6\%) as well as in the long run (between $0.2 \%$ and $1.5 \%$ ). 

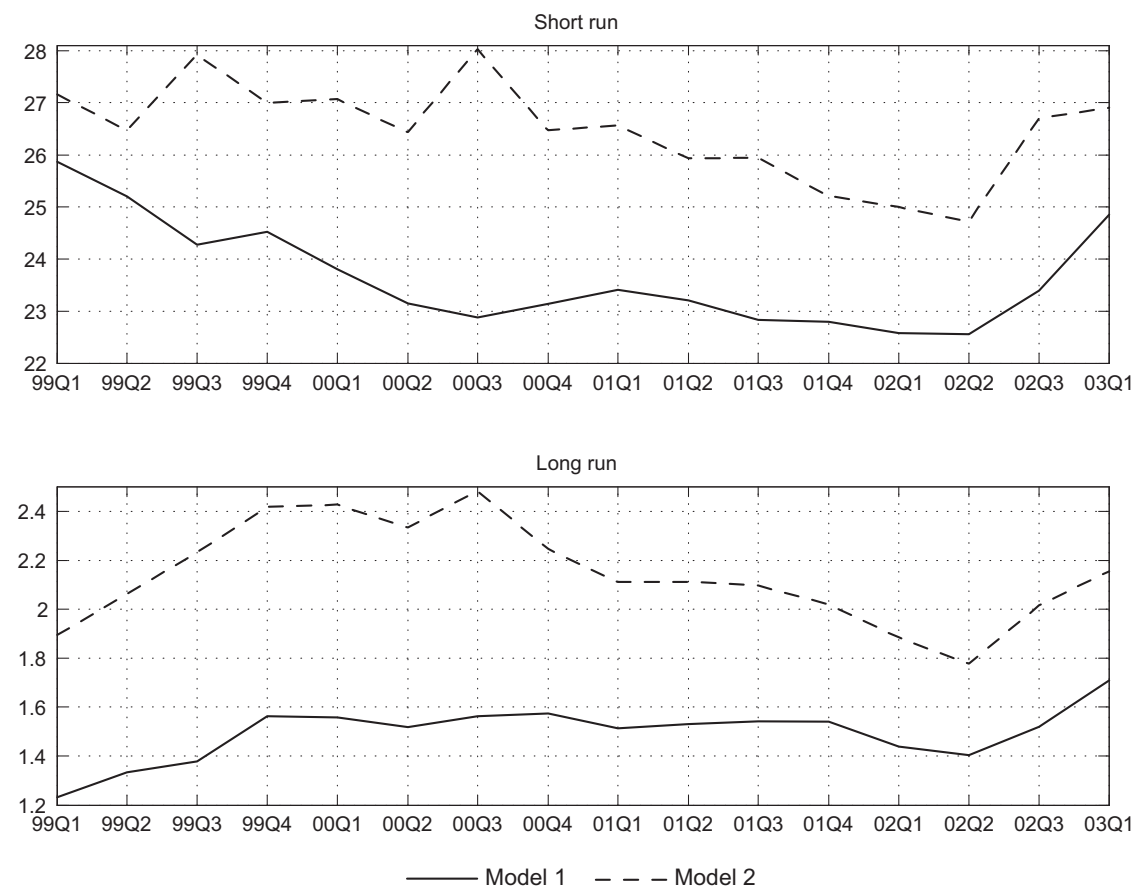

FIGURE 4. Variance decompositions of output with respect to the monetary policy shock (in percent) in Models 1 and 2.

Monetary policy has a significant impact on output in the short run (around 27-28\% for Model 2, Figure 4), but this impact diminishes following the bursting of the bubble. The impact in the long run is very small and negligible.

As in the previous crisis period, output is mainly explained by the monetary policy and technology shocks (respectively around 27-28\% and 65\% for Model 2 ) in the short run, but mainly by the technology shock in the long run (around $86 \%$ ). The markup shock should also be taken into consideration in both runs, even though its role is less important than that of the preceding two shocks $(11 \%$ and $14 \%$ in the short and long run, respectively).

As far as flexible-price output is concerned, our results show that the impact of the money shock is also small in the short run (between $2 \%$ and 6\%) and in the long run $(0.2 \%$ and $1.5 \%)$. These results are applicable to the monetary policy shock as well. Flexible-price output is essentially explained by the technology shock in the short as well as the long run (around 90\% for both models).

The money shock has a very small impact (less than $2 \%$ ) on the variance of inflation. Monetary policy, on the other hand, has a significant role to play in inflation variability, at least in the short run (Figure 5). This impact increases a bit after the peak of the bubble. 

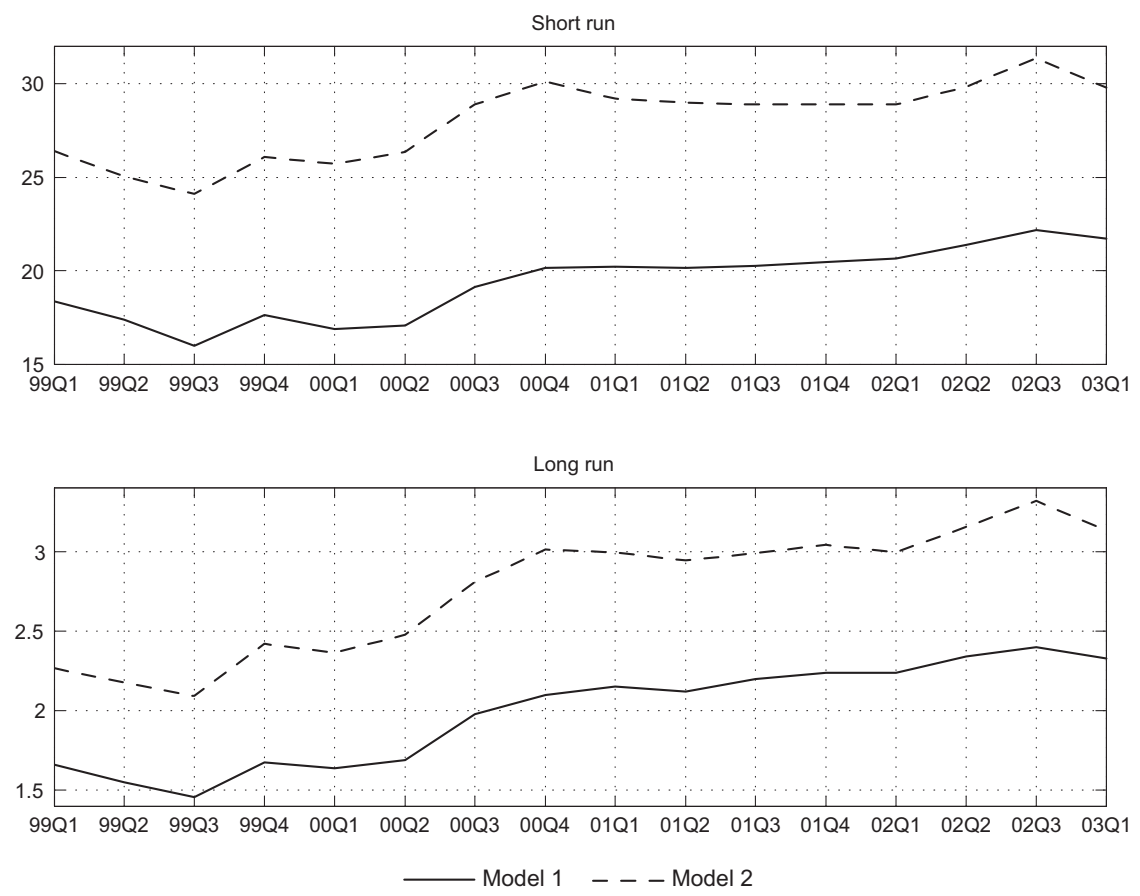

FIGURE 5. Variance decompositions of inflation with respect to the monetary policy shock (in percent) in Models 1 and 2.

All in all, the variance of inflation is primarily explained by the monetary policy and markup shocks in the short run (around 30\% and 80\% for Model 2, respectively), and by the markup shock (around 97\% for Model 2) in the long run. The other shocks (money and technology) have a negligible impact in both models.

\subsection{Forecasting Performance}

According to Figure 6, between 1999 Q4 and 2000 Q4, when the bubble was building up, Model 2 does not demonstrate significantly better predictive power of output dynamics than the baseline model. The results change in the two quarters following the bursting of the bubble, until the events of September 11, 2001 (2001 Q3). Pairwise Giacomini and White (2006) tests of equal predictive ability (conditional and unconditional) over the period cannot statistically assess which model is better ( $p$-value of 0.83 for the unconditional test and of 0.69 for the conditional test).

In terms of inflation forecasts outside crisis periods, Model 1 is generally a better predictor than Model 2; whereas during crisis periods, the former model prevails. 


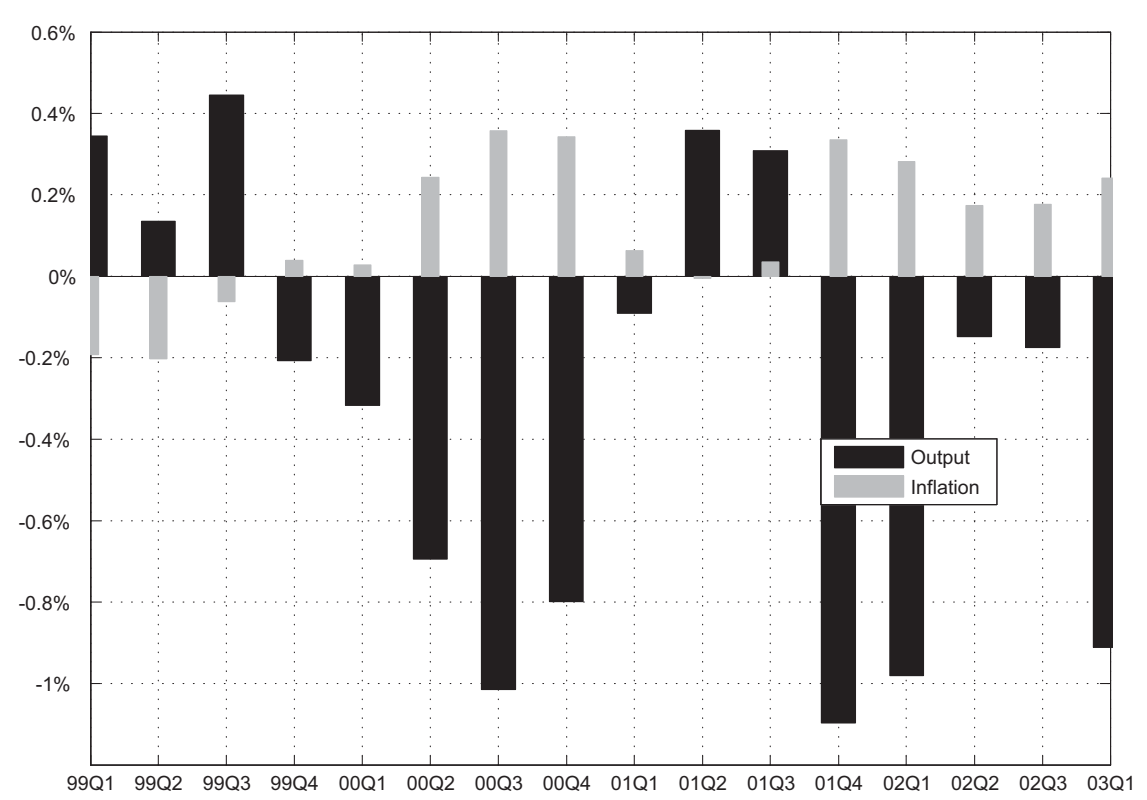

FIGURE 6. Comparison of output and inflation DSGE forecast errors. Model 2 is better when the bar is positive; Model 1 is better otherwise.

The Giacomini and White (2006) tests of equal predictive ability of inflation are not rejected.

\subsection{Interpretation}

Even if the impact of money on output and flexible-price output before 2000 Q3 (the peak of the financial bubble) is small, it is close to the value found by Ireland (2004) and Andrés et al. (2006). This may be because the dot-com crisis ultimately had a rather small impact on European economies. The small impact on output is explained in Model 2 by the very low value of the expected money growth parameter $\left(\kappa_{\mathrm{mp}}=\frac{(\sigma-v)\left(1-a_{1}\right)}{v-a_{1}(v-\sigma)}\right)$ and of the expected money shock growth parameter on output $\left(\kappa_{s m}=-\frac{\left(1-a_{1}\right)(v-\sigma)}{\left(v-a_{1}(v-\sigma)\right)(1-v)}\right)$.

The dot-com crisis appears to have reinforced the impact of monetary policy on inflation. This impact has increased since the beginning of the period (Figure 5) in the long and short runs to reach a maximum level at the end of the period.

As explained in Section 3.3, the transmission of the monetary policy shock is not linked to an estimated parameter (the value multiplying the monetary policy shock is equal to one). The values of the parameters alone are, therefore, not sufficient to explain the behavior of the impact of monetary policy on output and inflation dynamics. 

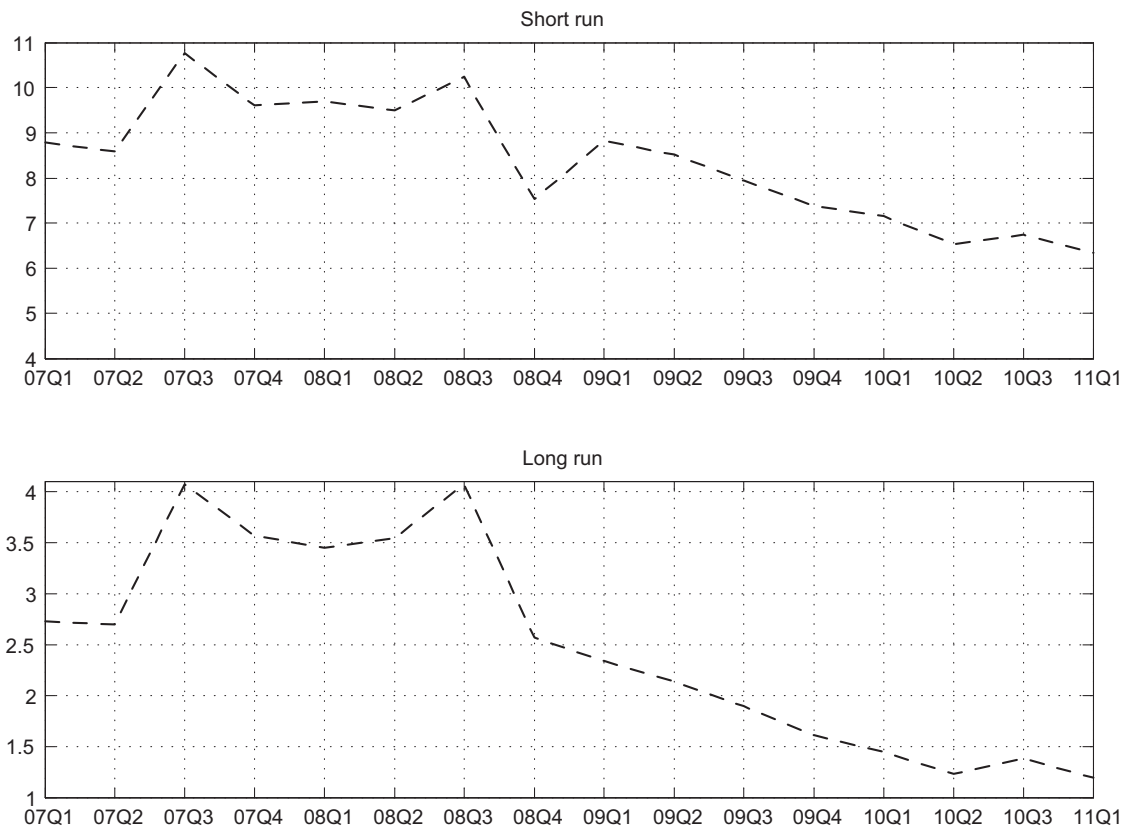

FIGURE 7. Variance decompositions of output with respect to the money shock (in percent) in Model 2.

\section{THE GLOBAL FINANCIAL CRISIS}

The rise in subprime mortgage delinquencies and foreclosures in the United States and the resulting decline of securities backed by these mortgages around the world started in 2007 Q3. After the subprime crisis, the debt crisis started around 2010 Q2 in the Eurozone. To capture the impact of these events, our period of analysis ranges from 2007 Q1 through 2011 Q1.

\subsection{Variance Decomposition}

Figure 7 shows that the impact of the money shock on output variance in the short run increases from 2007 Q2 and peaks in 2007 Q3 and 2008 Q3, explaining about $10 \%$ of the variance between these two peaks. The rapid decrease in the value of this impact between 2008 Q3 and 2009 Q1 is notable, after which it stabilizes. The value in the long run remains very small through the period and follows a pattern similar to that in the short run. After 2009 Q1, the impact manifests a decreasing trend, to reach about $6.5 \%$ in $2011 \mathrm{Q} 1$.

The monetary policy shock has a significant impact on output variation in the short run (Figure 8), with a peak in 2008 Q3. At this point, it explains more than $30 \%$ and 25\% of the output variance in Models 1 and 2, respectively. The impact of monetary policy on output increases over the first quarters of the GFC and 

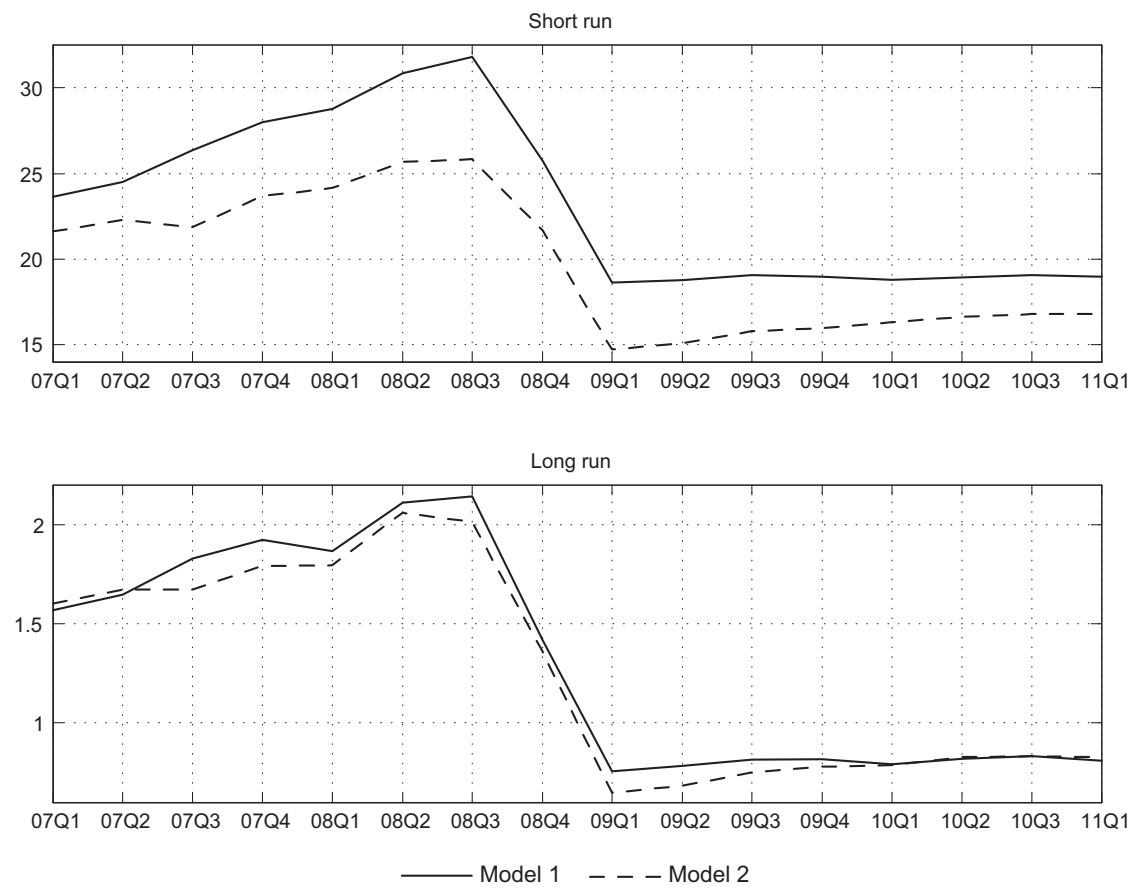

FIGURE 8. Variance decompositions of output with respect to the monetary policy shock (in percent) in Models 1 and 2.

reaches its highest level at the peak of the GFC (2008 Q3). Following this peak, the impact decreases fairly sharply, to reach its lowest level in the beginning of 2009.

As shown, the impact of monetary policy on output is lower for Model 2 than for Model 1. By construction, money shocks have no impact on output in the baseline model (Model 1), whereas they have such an impact in Model 2; and this impact of the money shocks is fairly strong during this period. Therefore, the impact of the money shocks on output lowers the impact of the monetary policy shocks on output in Model 2, in the short as well as long runs.

As in the previous crises, output variability in the short run is primarily explained by the monetary policy shock (between $20 \%$ and more than $30 \%$ ) and the technology shock (around 64\%). The technology shock dominates the process in the long run (around 85\%). The markup shock also has a nonnegligible role to play, because it accounts for $12 \%$ of the output variance in the short run and about $14 \%$ in the long run in Model 1 . The result is somewhat different in the case of Model 2, because the role of the markup shock is limited to around 5\%.

The impact of the money shock on flexible-price output follows the same pattern as that on current output, but with somewhat higher values in the short run (between $7 \%$ and $13 \%$ ), and comparable values in the long run (between $1 \%$ and $4.5 \%$ ). 

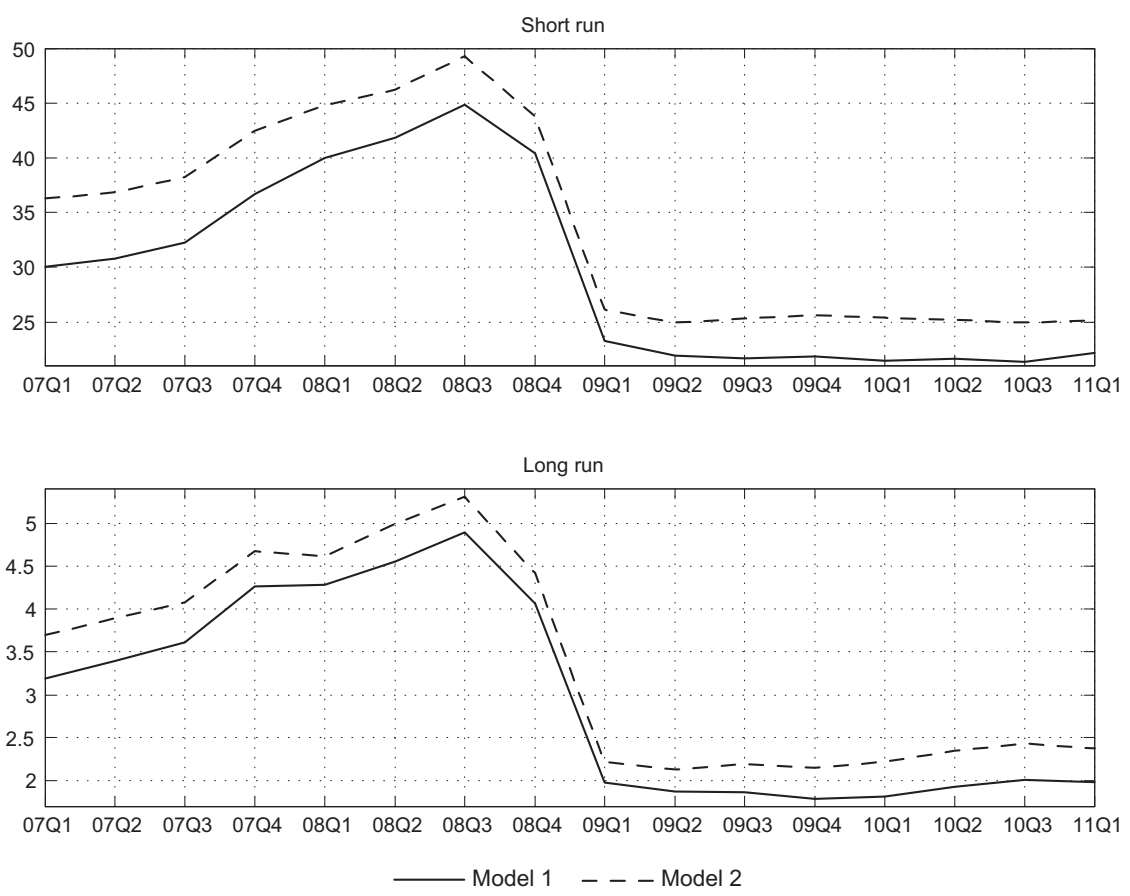

FIGURE 9. Variance decomposition of inflation with respect to the monetary policy shock (in percent) in Models 1 and 2.

However, the impact of the monetary policy and markup shocks on this variable becomes insignificant in both models, in the short and long runs.

On the whole, flexible-price output is essentially explained in both models by the technology shock, in the short and long runs (with a value around 80\%).

As during the other crises, the impact of the money shock on inflation is insignificant. Inflation variations in the short run are driven mainly by the monetary policy shock (as Figure 9 shows, it explains between $20 \%$ and $50 \%$ of the variance) and the markup shock (around 79\%), and by the markup shock (around 97\%) in the long run, in both models. The significant change in the importance of these impacts from 2008 Q3 to 2011 Q1 is noticeable.

\subsection{Forecasting Performance}

Figure 10 indicates that at the core of the GFC (2007 Q4 through 2009 Q4), Model 2 provides better forecasts of output than Model 1 in terms of RMSE. This outcome is reversed following 2010 Q1, when the debt crisis starts. Pairwise Giacomini and White (2006) tests of equal predictive ability (conditional and unconditional) confirm that Model 2 provides better forecasts of output than Model 1. Equal 


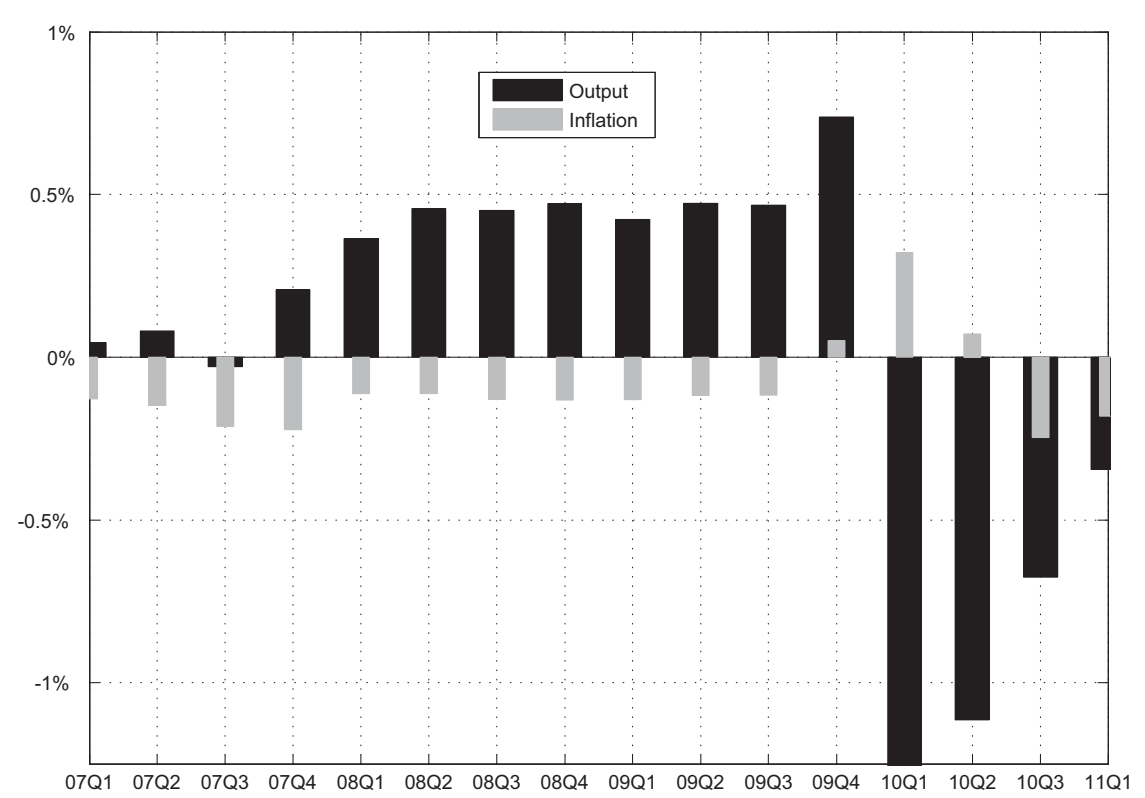

FIGURE 10. Comparison of output and inflation DSGE forecast errors. Model 2 is better when the bar is positive; Model 1 is better otherwise.

predictive ability of Models 1 and 2 is rejected and Model 2 outperforms Model 1, with a $p$-value of 0.001 (for conditional and unconditional predictive ability tests).

Even though Model 1 is in general better than Model 2 in terms of inflation forecasts, the difference is insignificant, a result confirmed by the Giacomini and White (2006) tests of equal predictive ability.

\subsection{Interpretation}

As far as the United States is concerned, Cecchetti (2009) and Mishkin (2010) consider that the crisis began in 2007 Q1, when several large subprime mortgage lenders started to report losses. The real trigger for the crisis was in 2007 Q3, when the French bank BNP Paribas temporarily suspended redemptions from three of its fund holdings that had invested in assets backed by U.S. subprime mortgage debt. As a result, credit spreads began widening, overnight interest rates in Europe shot up, and the European Central Bank (ECB) immediately responded with the largest short-term liquidity injection in its nine-year history.

The Euro Group of heads of states and governments and the ECB held an extraordinary summit in October 2008 to determine joint action for the Eurozone. They agreed on a bank rescue plan that would entail hundreds of billions of euros-governments would inject banks with capital and guarantee interbank lending. Financial uncertainty decreased as a consequence of this action. This decrease may explain the diminishing impact of money and monetary policy on 
output variations after October 2008 (Figures 7 and 8), as well as the decreasing impact of monetary policy on inflation (Figure 9).

The change in the impact of money on output is explained in the model (cf. the Online Appendix) by the variations in the expected money growth parameter $\left(\kappa_{\mathrm{mp}}\right)$ and the expected money growth shock parameter on output $\left(\kappa_{\mathrm{sm}}\right)$.

The impact of money on flexible-price output partly results from the variation of the money shock parameter $\left(v_{\mathrm{sm}}^{y}=\frac{(1-\alpha)(\nu-\sigma)\left(1-a_{1}\right)}{\left(\left(\nu-a_{1}(\nu-\sigma)\right)(1-\alpha)+\eta+\alpha\right)(1-\nu)}\right)$.

Similarly to the previous crisis periods, the values of the parameters alone are not sufficient to describe monetary policy impacts on output and inflation dynamics.

As explained in Section 3.3, the transmission mechanism, or at least its consequences, are better understood by analyzing the variance decomposition with respect to structural shocks than by going through the changes in the values of parameters. The exceptions to this are parameters that directly multiply a shock in the macro-equation of a core variable (as is the case with $\kappa_{\mathrm{mp}}, \kappa_{\mathrm{sm}}$, and $v_{\mathrm{sm}}^{y}$ ).

Our monetary policy shock describes only conventional monetary policy shocks. The decreasing role of conventional monetary policies after 2008 Q3 is probably due to the emergence of unconventional monetary policy around the same period. This change in the policy regime may have influenced money-related parameters in the flexible-price output equation $\left(v_{\mathrm{sm}}^{y}, v_{m}^{y}=\frac{(1-\alpha)(v-\sigma)\left(1-a_{1}\right)}{\left(v-a_{1}(v-\sigma)\right)(1-\alpha)+\eta+\alpha}\right.$, and $v_{c}^{y}=$ $\left.\frac{(1-\alpha) \ln (\varepsilon /(\varepsilon-1))}{\left(\nu-a_{1}(\nu-\sigma)\right)(1-\alpha)+\eta+\alpha}\right)$.

The output RMSD comparison (Figure 10) is not affected by the change in policy that occurred during the last quarter of 2008. The quarter $2008 \mathrm{Q} 3$ is not the end of the crisis, even if the impact of money and monetary policy on output declines. Uncertainty and risk aversion are ever-present in the economy. This probably explains why Model 2 has a better predictive power for output than Model 1 during the GFC.

In contrast to other studies, such as Ireland (2004) and Andrés et al. (2006, 2009), our analysis indicates that money did have a significant role to play in the GFC. This may confirm the predictive abilities of Model 2 during crisis periods.

To better understand the relationship between the role of money and monetary policy during the financial crisis, it may be useful to introduce the evolution of the interest rate spread over the period as an indication of the uncertainty level. This spread ${ }^{12}$ provides an assessment of counterparty risk from interbank lending, reflecting both liquidity and credit risk concerns.

Figure 11 indicates that the dynamics of the short-run impact of money on output during the GFC and the interest rate spread are positively related (except in 2009 Q1 and after 2009 Q4). This relationship underscores the link between financial risk and the role of money on output.

In the same vein, Figures 12 and 13 show that the impact of monetary policy on output and inflation follows the same direction as the spread. These impacts are significant and increase with the crisis, from 2007 Q1 up to the peak of the GFC (2008 Q3). They diminish rapidly and significantly after 2008 Q3, remaining at a lower but still meaningful level until the end of the period (2011 Q1). This sharp decline coincides with the introduction of unconventional monetary policies. 


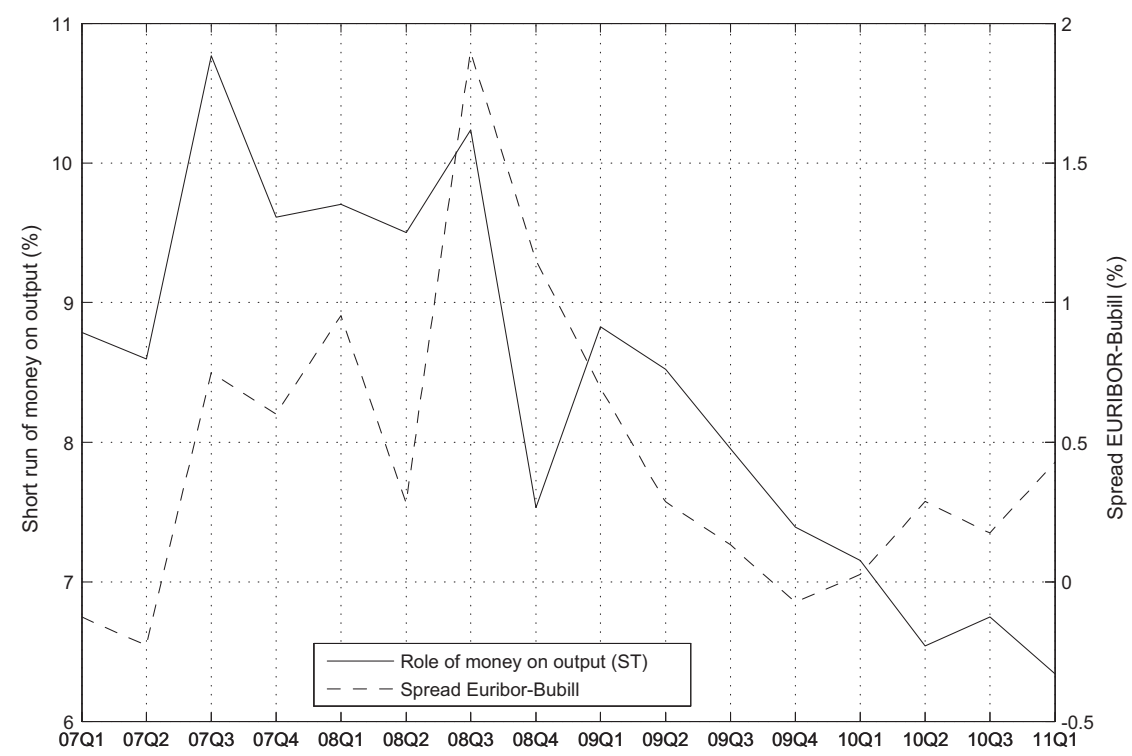

FIGURE 11. Comparison between the effect of money on output (short-run variance decomposition, Model 2) and the Euribor-Bubill spread.

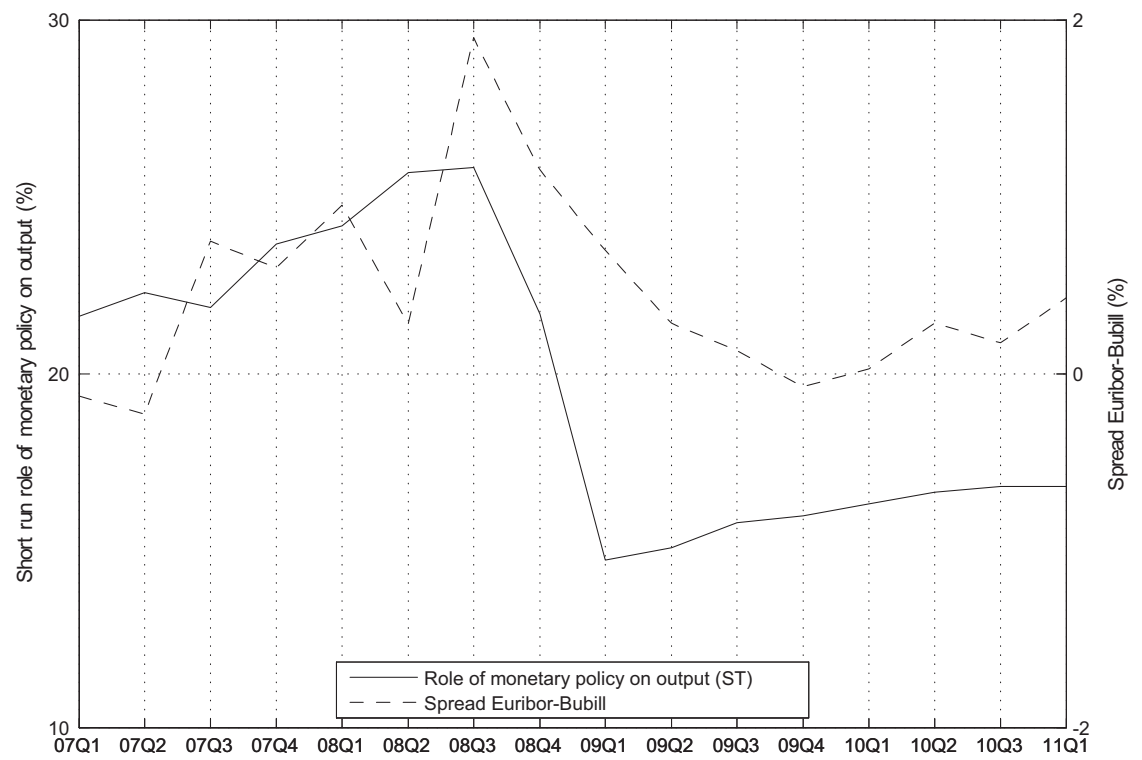

FIGURE 12. Comparison between the effect of monetary policy on output (short-run variance decomposition, Model 2) and the Euribor-Bubill spread. 


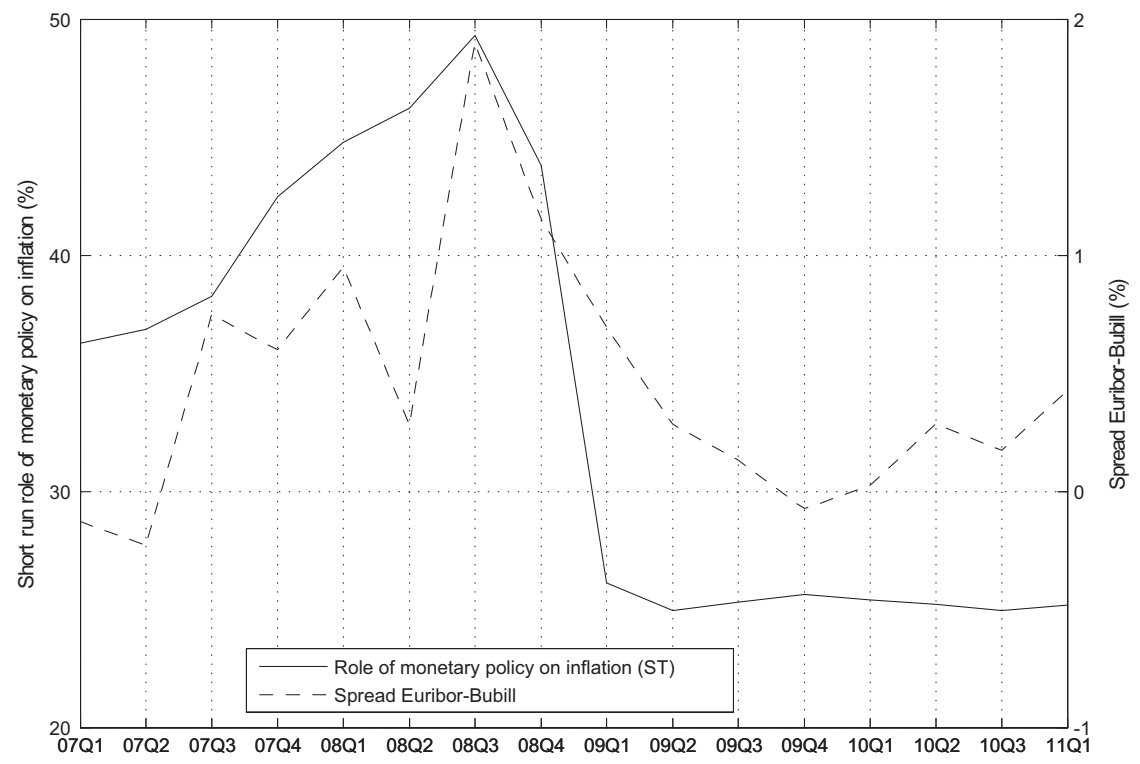

FIGURE 13. Comparison between the effect of monetary policy on inflation (short-run variance decomposition, Model 2) and the Euribor-Bubill spread.

When Lehman Brothers and other major financial institutions failed in 2008 Q3, the credit freeze in the money market brought the global financial system to the brink of collapse. The Federal Reserve, the ECB, and other central banks purchased almost three trillion dollars of government debt and troubled private assets from banks over the last quarter of 2008. That was the largest liquidity injection into the credit market and the largest unconventional monetary policy action in world history. These measures explain the fall of the spread and the sharp decline in the impact of monetary policy on output and inflation after this period (Figures 12 and 13).

Uncertainty started to decrease in the aftermath of these policy actions, decreasing the short-run impact of money on output following the peak of the spread in 2008 Q3 (Figure 11).

\section{A COMPARISON OF THE THREE CRISES}

In order to compare the three crises, we analyze the impulse responses of output, output gap, and inflation to money and monetary policy shocks over key periods. The comparison is for both models as far as the monetary policy shock is concerned. A comparison of variance decompositions over the different crises is also useful to better understand the respective roles of the shocks. 

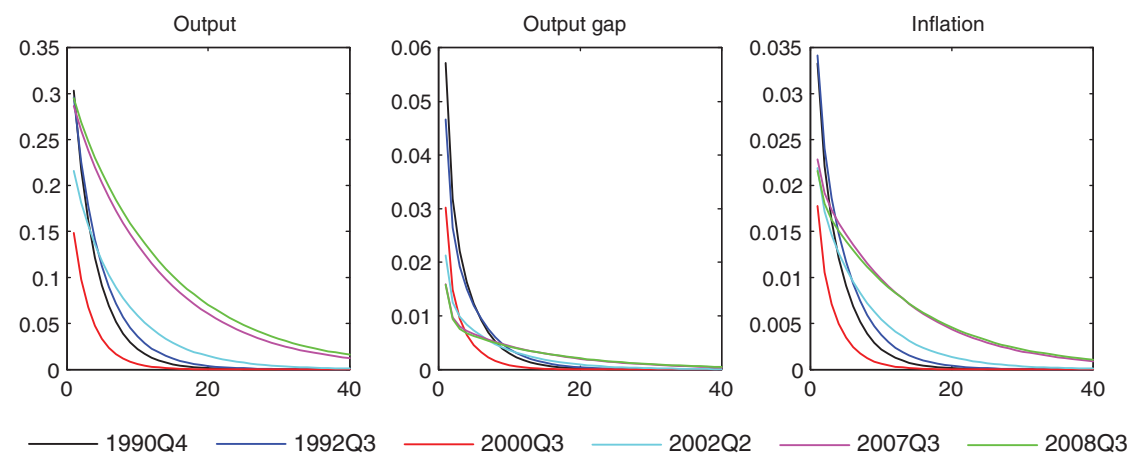

FIGURE 14. Comparison of impulse response functions following a $1 \%$ standard deviation money shock (Model 2) over the three crises.

\subsection{Impulse Response Functions}

Besides indicating the impact of different shocks, the IRF give the opportunity to quantify the persistence of the shocks over each period.

The impulse response functions of inflation are reported in percentage points, whereas the other impulse responses are reported in percentage deviations from each variable's period-specific linear trend (see Section 2). The selected dates correspond to the two most relevant peaks of each crisis. ${ }^{13}$

Figure 14 shows the impulse response functions of output, flexible-price output, output gap, and inflation following a $1 \%$ increase in the money shock's standard deviation (Model 2). Interestingly, a positive money shock implies almost the same response of output for the ERM crisis and the GFC (0.3\%), at least on impact, whereas the on-impact response of output for the dot-com crisis is smaller (0.15$0.2 \%$ ). Yet the impact on the flexible-price output is stronger for the GFC than for the other crises.

The persistence of this shock is greater for the GFC than for the other crises. This is a reflection of the fact that it takes more time for output and flexible-price output to reach their steady-state values over the GFC than over the other two crises.

The impact of the money shock on the output gap differs between crises. It is more significant in the first few quarters following the peaks of the ERM crisis (almost $0.06 \%$ ) than in the first few quarters following the peaks of the dot-com crisis $(0.03 \%)$ and the $\operatorname{GFC}(0.015 \%)$.

The response of inflation to a $1 \%$ money shock is higher during the ERM crisis than during the two other crisis periods. These differences may be at least partly explained by the fact that during the ERM crisis, the uncertainty about the exchange rate was higher than for other crisis periods.

As for output and flexible-price output, the responses of inflation to a money shock are more persistent over the GFC than over other crises. 

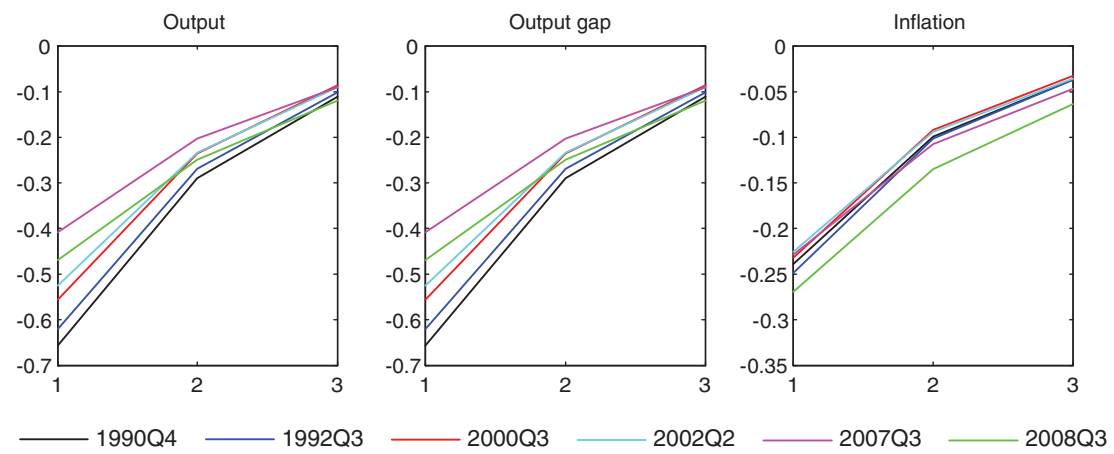

FIGURE 15. Comparison of impulse response functions following a 1\% standard deviation monetary policy shock (Model 2) over the three crises.

Figure 15 shows an enlargement of the impulse response functions to a $1 \%$ increase in the monetary policy shock's standard deviation in the nonseparable framework (Model 2).

The responses of flexible-price output to a monetary policy shock are not shown because they are almost nil (on the order of $10^{-16}$ ) for all key periods.

The response of output to a monetary policy shock differs between time periods. There is a decrease on impact from about $0.4 \%$ in 2007 Q3 to $0.65 \%$ in 1990 Q4. The impact of monetary policy on output was, therefore, stronger over the ERM crisis period than the dot-com crisis, and stronger over the dot-com crisis than the GFC period. Similar implications are true for the output gap. This is also true for the inflation rate, but to a lesser extent. The exchange rate channel may have had a more significant impact on monetary policy and on transmission channels during the ERM crisis than during the more recent periods.

After a positive technology shock, output and flexible-price output increase, the output gap decreases slightly, and inflation decreases (figures not shown). Interestingly, the sensitivity of output to a technology shock is significantly higher during the GFC (in 2008 Q4 and 2010 Q2) than during the two other crises.

The impact of a price-markup shock on output and inflation decreases from 1990 to 2010 . Regardless of the period, a positive price-markup shock leads to an increase in inflation, but to a decrease in output and the output gap. The impact of a price-markup shock on flexible-price output is nil (on the order of $10^{-16}$ ).

Figure 16 shows an enlargement of the impulse response functions to a monetary policy shock in the separable and nonseparable frameworks, that is, a comparison of the responses of output, output gap, and inflation between Models 1 and 2 . These impulse response functions are focused only on the peak point in each crisis that appears to be more critical.

The impact of a monetary policy shock on output, output gap, and inflation in the baseline model is typically smaller than in the model including money. However, 

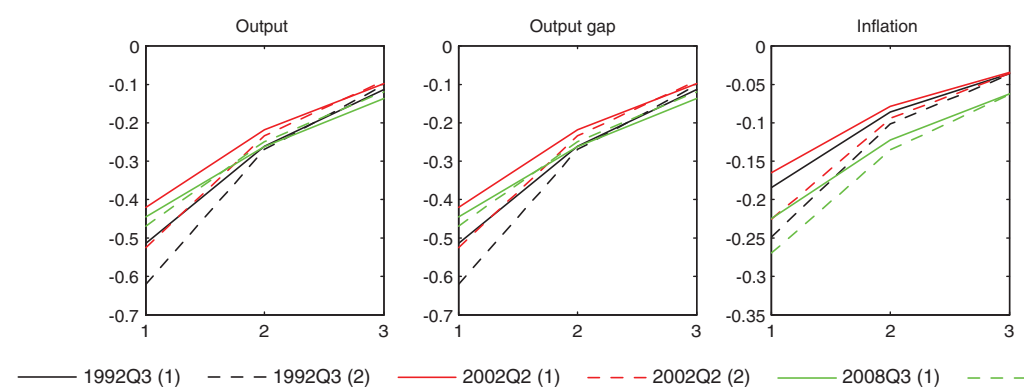

FIGURE 16. Comparison of impulse response functions following a 1\% standard deviation monetary policy shock over the three crises (Model 1: solid lines; Model 2: dashed lines).

the persistence of the monetary policy shock does not appear to be significantly affected by the inclusion of money in the model. ${ }^{14}$

\subsection{Variance Decompositions}

During the GFC, money has a relatively significant impact on output and flexibleprice output, whereas the impact is smaller during the ERM and dot-com crises, especially in the short term. These impacts are significantly stronger, especially during the GFC (between $6.5 \%$ and 11\%), than those of Ireland (2004), Andrés et al. (2006), and Andrés et al. (2009), who found a negligible effect of money on output (between 0 and $2 \%$ ). However, the impact of money on inflation variability is very small.

Over all three crises analyzed in this paper, the short-run impact of monetary policy on output remains high (around 15-30\%), but its value fluctuates more during the GFC, indicating the greater disruptive effect of this crisis than of the others.

The short-run impact of monetary policy shocks on inflation variability also remains high over the three crises (15-50\%), again with higher fluctuations during the GFC (about 25-50\%).

A focus on the GFC (Section 5.3) confirms the link between the spreads that measure uncertainty in the financial market and the impact of the money and monetary policy shocks on the dynamics of the economy.

Finally, in terms of output forecasting, Model 2 generally performs better than Model 1 over crisis periods, especially during periods of high uncertainty. The results concerning the financial crisis are striking in that respect (Figure 10).

\section{CONCLUSION}

This paper has studied the role of money and monetary policy during crisis periods in the Eurozone, as well as the forecasting performance and abilities of two models. 
We use two DSGE models_-one baseline separable model, as in Galí (2008), and one with nonseparable preferences between consumption and real money balances, and with a money-augmented Taylor rule. The study is conducted over three crisis periods running from 1990 through 2011, including the European ERM crisis (1992), the dot-com crisis (2001), and the GFC (2007).

We tested both models by using successive Bayesian estimates to obtain empirical estimates of the variations of the micro-parameters. We ran simulations to obtain variance decompositions from both models over the three crises and capture short- and long-run dynamics that is generally hidden in longer sample sizes. We also ran DSGE forecasts to compare the out-of-sample forecasting performance of the two models over the crises and analyze the responses of output, output gap, and inflation to shocks.

Our analysis indicates that the impact of money shocks on output variations seems to increase during crises, especially during the GFC. This impact was greater during the GFC than the ERM and dot-com crises. The impact of conventional monetary policy is also affected during crises. As far as the GFC is concerned, the impact appears to increase at the beginning of the crisis, but decreases sharply afterward.

In addition, our results demonstrate that during these periods, the nonseparable model generally provides better out-of-sample forecasts of output (and sometimes inflation) than the baseline model, in terms of RMSE. Giacomini and White (2006) tests demonstrate that the nonseparable model outperforms the baseline model during the ERM and GFC crises.

The results also underscore the fact that the impact of money and monetary policy on output variability diminishes significantly following what appears to be the peak of the GFC (2008 Q3). Inflation variability does not seem to be affected directly by money variables. It is mainly explained by the monetary policy and markup shocks in the short run, and essentially by the markup shock in the long run, as found in the literature.

The response of output to a money shock is stronger at the peak of the GFC than at the peak of the ERM and dot-com crises. And the persistence of the output response to a money shock is higher over the GFC than over the other crises.

Last, it is interesting to note that the response of flexible-price output to a money shock during the GFC is about as strong as the response of output itself. In addition, it is significantly stronger and longer-lasting than it is during other crises. Yet a monetary policy shock appears to have no effect on flexible-price output for all crises (in both models).

The findings of our paper can be a valuable input for a central bank in its decision-making process as far as macroeconomic forecasting is concerned, at least during crisis periods.

Finally, our results also provide some clues regarding the dynamics of the economy that may help inform central banks, markets, and policy regulators. For example, the more significant than generally expected role of real money 


\section{balances during crises and the changing role of monetary policy are important indicators.}

\section{NOTES}

1. Here, the term "separability" must be differentiated from the terminology used in the monetary aggregation literature [Barnett (1980)].

2. Kelly et al. (2011) suggest that official monetary aggregates, at least in the United States, use an aggregation methodology that is increasingly incorrect as the aggregate becomes broader. Belongia and Ireland (2014) show that a Divisia aggregate of monetary services tracks the true monetary aggregate almost perfectly, whereas a simple-sum measure often behaves quite differently in the United States [the so-called Barnett (1980) critique; see also Hendrickson (2014)]. As they are not published by the European Central Bank, these types of monetary aggregates cannot be used in our paper.

3. For both models, and for each estimation, a diagnosis of the overall convergence for the Metropolis-Hastings sampling algorithm can be provided upon request.

4. We use the sensitivity analysis toolbox provided in Dynare 4.4.3 for both models and for each estimation. All parameters are identified in the model (rank of $\mathrm{H}$ ) and by $\mathrm{J}$ moments (rank of J). These results can be provided upon request.

5. DSGE models are increasingly being utilized by central banks and other policy making institutions to assist with policy decisions and forecasting, as pointed out by Edge and Gürkaynak (2010). Sims and Zha (1998) introduced Bayesian methods into vector autoregressive (VAR) models to improve the accuracy of out-of-sample forecasts in a dynamic multivariate framework. More recently, researchers have started to examine the forecasting performance of these models. In one such investigation, Smets and Wouters (2007) show that a DSGE model can generate forecasts that have a lower root-meansquared deviation (RMSD) than a Bayesian vector autoregression (BVAR). On the other hand, Edge et al. (2010) show that the out-of-sample forecasting performance of the Federal Reserve Board's new DSGE model for the U.S. economy (EDO) is in many cases better than that of their large-scale macroeconometric model (FRB/US).

6. As a matter of fact, this comment is also valid as far as the forecasting performance of the models is concerned.

7. The 1990 oil price spike occurred in response to the Iraqi invasion of Kuwait on August 2, 1990. The war lasted until February 28, 1991.

8. The constitutional crisis of 1993 was a political standoff between the Russian president and the Russian parliament that was resolved using military force.

9. From 1992 through 1996, real estate prices declined up to $40 \%$.

10. We do not present the decomposition of output, flexible-price output, and inflation with respect to the markup and technology shocks. As they are negligible, we present neither the decomposition of inflation with respect to the money shock nor the decomposition of the flexibleprice output with respect to the monetary policy shock. Finally, we do not present the decomposition of output and flexible-price output with respect to the money shock. This applies to all crises when appropriate. Yet all these variance decompositions are available upon request.

11. See the Online Appendix for a detailed description of the macro-parameters.

12. The spread is measured as the difference between the three-month Euribor and a short maturity bond. As a European bond does not exist, we choose the one-year Bubill (Germany) as a short-term Treasury bill.

13. We do not present all the impulse response functions over the three crises, for each period, and for both models; that would be too heavy a task. However, all these results are available upon request.

14. The responses of flexible-price output to a monetary policy shock are not shown because they are nonsignificant (on the order of $10^{-16}$ ) for both models.

15. The results of parameter estimation and validation and robustness tests can be provided upon request. All Student tests are above 1.96 and parameter estimateds are stable over time. 


\section{REFERENCES}

Adolfson, M., S. Laseen, J. Linde, and M. Villani (2007) Bayesian estimation of an open economy DSGE model with incomplete pass-through. Journal of International Economics 72(2), 481511.

Andrés, J., J. D. López-Salido, and E. Nelson (2009) Money and the natural rate of interest: Structural estimates for the United States and the euro area. Journal of Economic Dynamics and Control 33(3), $758-776$.

Andrés, J., J. D. López-Salido, and J. Vallés (2006) Money in an estimated business cycle model of the euro area. Economic Journal 116(511), 457-477.

Barnett, W.A. (1980) Economic monetary aggregates: An application of index number and aggregation theory. Journal of Econometrics 14(1), 11-48.

Barthélemy, J., L. Clerc, and M. Marx (2011) A two-pillar DSGE monetary policy model for the euro area. Economic Modelling 28(3), 1303-1316.

Bekiros, S.D. and A. Paccagnini (2015) Macroprudential policy and forecasting using hybrid DSGE models with financial frictions and state space Markov-switching TVP-VARs. Macroeconomic Dynamics 19(7), 1565-1592.

Belongia, M.T. and P.N. Ireland (2014) The Barnett critique after three decades: A New Keynesian analysis. Journal of Econometrics 183(1), 5-21.

Benchimol, J. (2014) Risk aversion in the Eurozone. Research in Economics 68(1), 39-56.

Benchimol, J. (2015) Money in the production function: A New Keynesian DSGE perspective. Southern Economic Journal 82(1), 152-184.

Benchimol, J. and A. Fourçans (2012) Money and risk in a DSGE framework: A Bayesian application to the Eurozone. Journal of Macroeconomics 34(1), 95-111.

Calvo, G. (1983) Staggered prices in a utility-maximizing framework. Journal of Monetary Economics 12(3), 383-398.

Canova, F. and G. Menz (2011) Does money matter in shaping domestic business cycles? An international investigation. Journal of Money, Credit and Banking 43(4), 577607.

Casares, M. (2007) Monetary policy rules in a New Keynesian euro area model. Journal of Money, Credit and Banking 39(4), 875-900.

Cecchetti, S. (2009) Crisis and responses: The Federal Reserve in the early stages of the financial crisis. Journal of Economic Perspectives 23(1), 51-75.

Chadha, J., L. Corrado, and S. Holly (2014) A note on money and the conduct of monetary policy. Macroeconomic Dynamics 18(8), 1854-1883.

Del Negro, M., F. Schorfheide, F. Smets, and R. Wouters (2007) On the fit of New Keynesian models. Journal of Business and Economic Statistics 25, 123-143.

De Santis, R., C. Favero, and B. Roffia (2013) Euro area money demand and international portfolio allocation: A contribution to assessing risks to price stability. Journal of International Money and Finance 32(C), 377-404.

Edge, R.M. and R.S. Gürkaynak (2010) How useful are estimated DSGE model forecasts for central bankers? Brookings Papers on Economic Activity 41(2), 209-259.

Edge, R.M., M.T. Kiley, and J.-P. Laforte (2010) A comparison of forecast performance between Federal Reserve staff forecasts, simple reduced-form models, and a DSGE model. Journal of Applied Econometrics 25(4), 720-754.

El-Shagi, M. and S. Giesen (2013) Money and inflation: Consequences of the recent monetary policy. Journal of Policy Modeling 35(4), 520-537.

El-Shagi, M., S. Giesen, and L.J. Kelly (2015) The quantity theory revisited: A new structural approach. Macroeconomic Dynamics 19(1), 58-78.

Fagan, G., J. Henry, and R. Mestre (2001) An Area-Wide Model (AWM) for the Euro Area. Working paper series 42, European Central Bank.

Fernández-Villaverde, J. and J.F. Rubio-Ramírez (2004) Comparing dynamic equilibrium models to data: A Bayesian approach. Journal of Econometrics 123(1), 153-187. 
Galí, J. (2008) Monetary Policy, Inflation and the Business Cycle: An Introduction to the New Keynesian Framework. Princeton, NJ: Princeton University Press.

Geweke, J., M. Keane, and D. Runkle (1997) Statistical inference in the multinomial multiperiod probit model. Journal of Econometrics 80(1), 125-165.

Giacomini, R. and H. White (2006) Tests of conditional predictive ability. Econometrica 74(6), 15451578.

Hendrickson, J.R. (2014) Redundancy or mismeasurement? A reappraisal of money. Macroeconomic Dynamics 18, 1437-1465.

Hurtado, S. (2014) DSGE models and the Lucas critique. Economic Modelling 44(S1), S12-S19.

Ireland, P. (2003) Endogenous money or sticky prices? Journal of Monetary Economics 50(8), 16231648.

Ireland, P. (2004) Money's role in the monetary business cycle. Journal of Money, Credit and Banking 36(6), 969-983.

Iskrev, N. (2010) Local identification in DSGE models. Journal of Monetary Economics 57(2), 189202.

Jacquier, E., N. Polson, and P. Rossi (2002) Bayesian analysis of stochastic volatility models. Journal of Business and Economic Statistics 20(1), 69-87.

Jones, B. and L. Stracca (2006) Are Money and Consumption Additively Separable in the Euro Area? A Non-parametric Approach. Working paper series 704, European Central Bank.

Kelly, L.J., W.A. Barnett, and J.W. Keating (2011) Rethinking the liquidity puzzle: Application of a new measure of the economic money stock. Journal of Banking and Finance 35(4), 768774.

Koop, G. (2003) Bayesian Econometrics. New York: John Wiley and Sons.

Mishkin, F. (2010) Over the cliff: From the subprime to the global financial crisis. Journal of Economic Perspectives 25(1), 49-70.

Rabanal, P. and J. Rubio-Ramírez (2005) Comparing New Keynesian models of the business cycle: A Bayesian approach. Journal of Monetary Economics 52(6), 1151-1166.

Ratto, M. (2008) Analysing DSGE models with global sensitivity analysis. Computational Economics 31(2), 115-139.

Sims, C. and T. Zha (1998) Bayesian methods for dynamic multivariate models. International Economic Review 39(4), 949-68.

Smets, F. and R. Wouters (2003) An estimated dynamic stochastic general equilibrium model of the euro area. Journal of the European Economic Association 1(5), 1123-1175.

Smets, F. and R. Wouters (2007) Shocks and frictions in US business cycles: A Bayesian DSGE approach. American Economic Review 97(3), 586-606.

Söderström, U. (2005) Targeting inflation with a role for money. Economica 72(288), 577596.

Taylor, J. (1993) Discretion versus policy rules in practice. Carnegie-Rochester Conference Series on Public Policy 39(1), 195-214.

Villa, S. (in press) Financial frictions in the euro area and the United States: A Bayesian assessment. Macroeconomic Dynamics.

Woodford, M. (2003) Interest and Prices: Foundations of a Theory of Monetary Policy. Princeton, NJ: Princeton University Press.

\section{A. PARAMETER DESCRIPTION}

Table A.1 describes the parameters. See the Online Appendix for a detailed description of the models. 
TABLE A.1. Description of the parameters

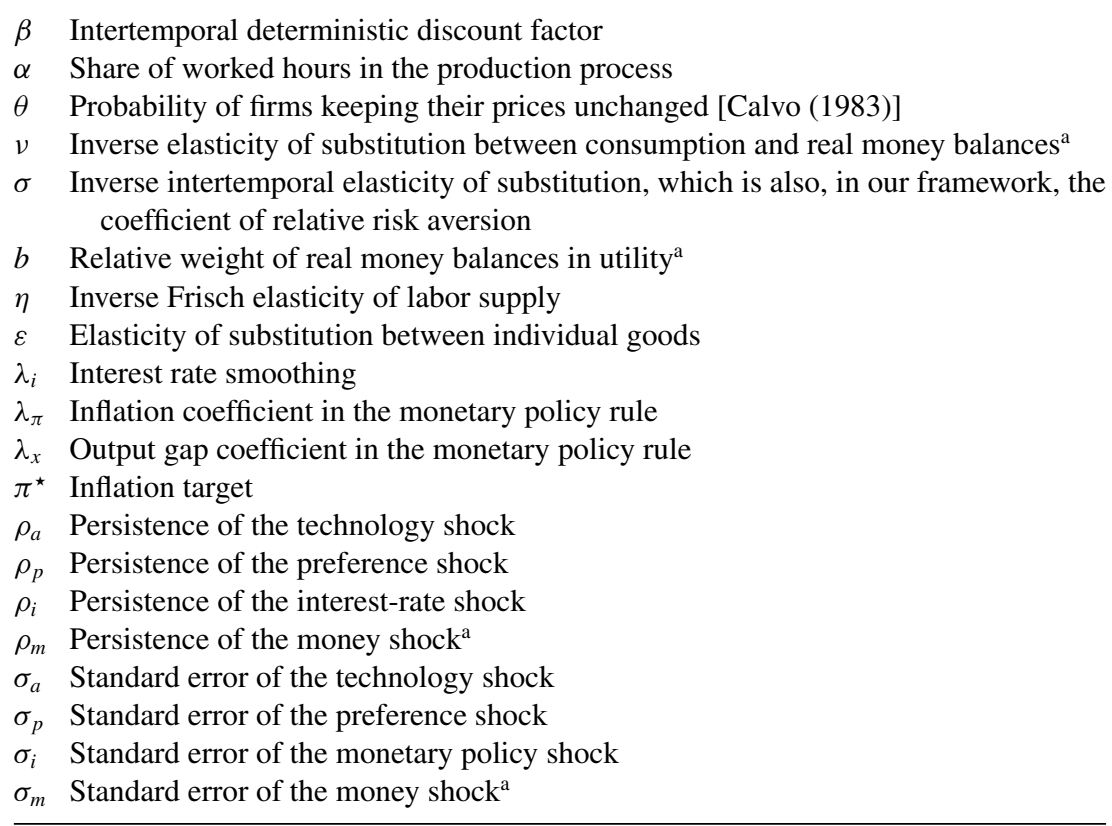

${ }^{a}$ Equal to zero in Model 1.

\section{B. CALIBRATION AND PRIORS}

Both models' parameters are calibrated identically (Table B.1). The monetary policy rule is an ad hoc reaction function and completely dependent on the monetary authority.

Following standard conventions, we calibrate beta distributions for parameters that fall between zero and one, inverted gamma distributions for parameters that need to be constrained to be greater than zero, and normal distributions in other cases.

The calibration of $\sigma$ is inspired by Rabanal and Rubio-Ramírez (2005) and by Casares (2007). They choose risk aversion parameters of 2.5 and 1.5, respectively. In line with these values, we assume that $\sigma=2$ corresponds to standard risk aversion, as in Benchimol and Fourçans (2012). We adopt the same priors in both models with the same risk aversion calibration.

As in Smets and Wouters (2003), the standard errors of the innovations are assumed to follow inverse gamma distributions. Furthermore, we choose a beta distribution for shock persistence parameters (as well as for the backward component of the Taylor rule) that should be less than one.

The calibration of $\alpha, \beta, \theta, \eta$, and $\varepsilon$ comes from Galí (2008) and Casares (2007). The relative weight of real money balances in the utility function $(b)$ is calibrated to 0.25 , as in Benchimol and Fourçans (2012), and the inflation target parameter $\pi^{*}$ is calibrated to 
TABLE B.1. Priors summary

\begin{tabular}{lcccccccc}
\hline & \multicolumn{3}{c}{ Priors } & & & \multicolumn{3}{c}{ Priors } \\
\cline { 2 - 3 } \cline { 7 - 8 } & Law & Mean & Std. & & Law & Mean & Std. \\
\hline$\alpha$ & $B$ & 0.33 & 0.05 & $\rho_{a}$ & & $B$ & 0.75 & 0.10 \\
$\theta$ & $B$ & 0.66 & 0.05 & $\rho_{p}$ & & $B$ & 0.75 & 0.10 \\
$\sigma$ & $N$ & 2.00 & 0.05 & $\rho_{i}$ & & $B$ & 0.50 & 0.10 \\
$\nu$ & $N$ & 1.25 & 0.25 & $\rho_{m}$ & & $B$ & 0.75 & 0.10 \\
$\pi^{*}$ & $N$ & 2.00 & 0.10 & $\sigma_{a}$ & & $I$ & 0.04 & 2.00 \\
$\lambda_{i}$ & $B$ & 0.50 & 0.10 & $\sigma_{p}$ & & $I$ & 0.04 & 2.00 \\
$\lambda_{\pi}$ & $N$ & 3.00 & 0.25 & $\sigma_{i}$ & $I$ & 0.04 & 2.00 \\
$\lambda_{x}$ & $N$ & 1.50 & 0.25 & $\sigma_{m}$ & $I$ & 0.04 & 2.00 \\
$\lambda_{\mathrm{mp}}$ & $N$ & 1.50 & 0.25 & & & & \\
\hline
\end{tabular}

Note: $N$ stands for normal distribution, $B$ for beta distribution, and $I$ for inverted gamma distribution.

an annual target of $2 \%$. The smoothed Taylor-type rule $\left(\lambda_{i}, \lambda_{\pi}, \lambda_{x}\right.$, and $\left.\lambda_{\mathrm{mp}}\right)$ is calibrated following Andrés et al. (2009), Barthélemy et al. (2011), and Benchimol (2014, 2015); analogous priors as those used by Smets and Wouters (2003) for the monetary policy parameters. In order to take into consideration possible changes in the behavior of the central bank, we assign a higher standard error for the coefficients of the Taylor rule. $v$ (the nonseparability parameter) must be greater than one. $\kappa_{i}$ must be greater than one, insofar as this parameter depends on the elasticity of substitution of money with respect to the cost of holding money balances, as explained in Söderström (2005); although still informative, this prior distribution is dispersed enough to allow a wide range of possible and realistic values to be considered (that is, $\sigma>v>1$ ).

The calibration of the shock persistence parameters and the standard errors of the innovations follows Smets and Wouters (2003), where a much lower mean is adopted for $\rho_{i}$. All the standard errors of shocks are assumed to be distributed according to inverted gamma distributions, with prior means of 0.04 . The latter law ensures that these parameters have positive support. The autoregressive parameters are all assumed to follow beta distributions. Except for monetary policy shocks, all these distributions are centered at 0.75 . We take a common standard error of 0.1 for the shock persistence parameters, as in Smets and Wouters (2003).

\section{POSTERIORS}

Figures C.1-C. 3 present the Bayesian estimates ${ }^{15}$ of both models. The solid and dashed lines represent the results for Models 1 and 2, respectively.

The estimation of the implied posterior distribution of the parameters for each sample size and each model is done using the Metropolis-Hastings algorithm [three distinct chains, each of 5000 draws; see Smets and Wouters (2007), and Adolfson et al. (2007)]. Average acceptance rates per chain are around 0.25 , as settled by the literature; priors and posteriors distributions are not presented, but are available upon request. 

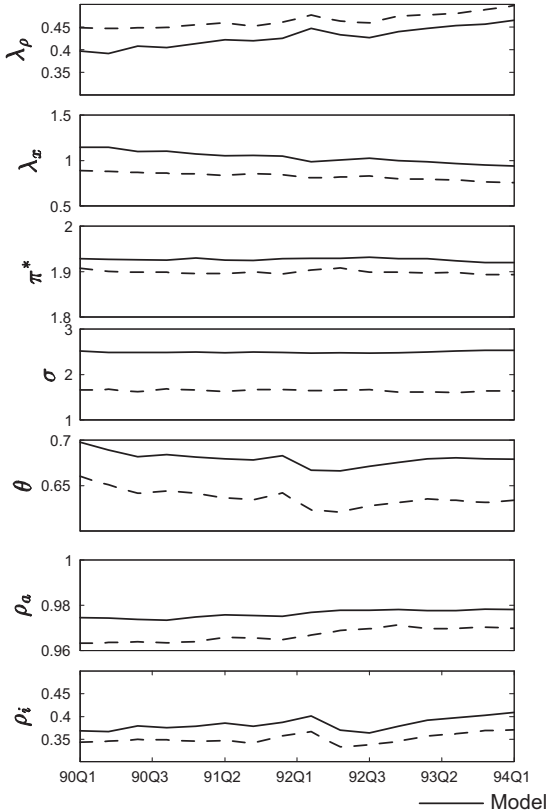
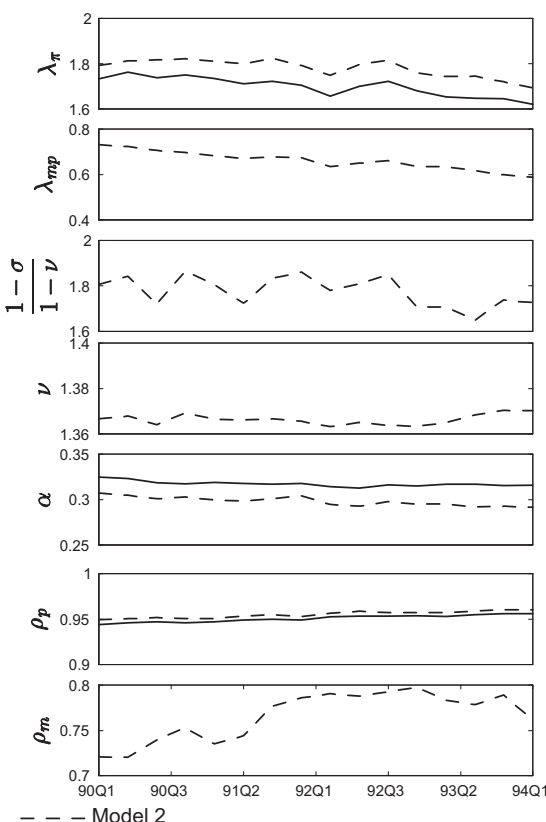

FIGURE C.1. Parameter values for both models during the ERM crisis.
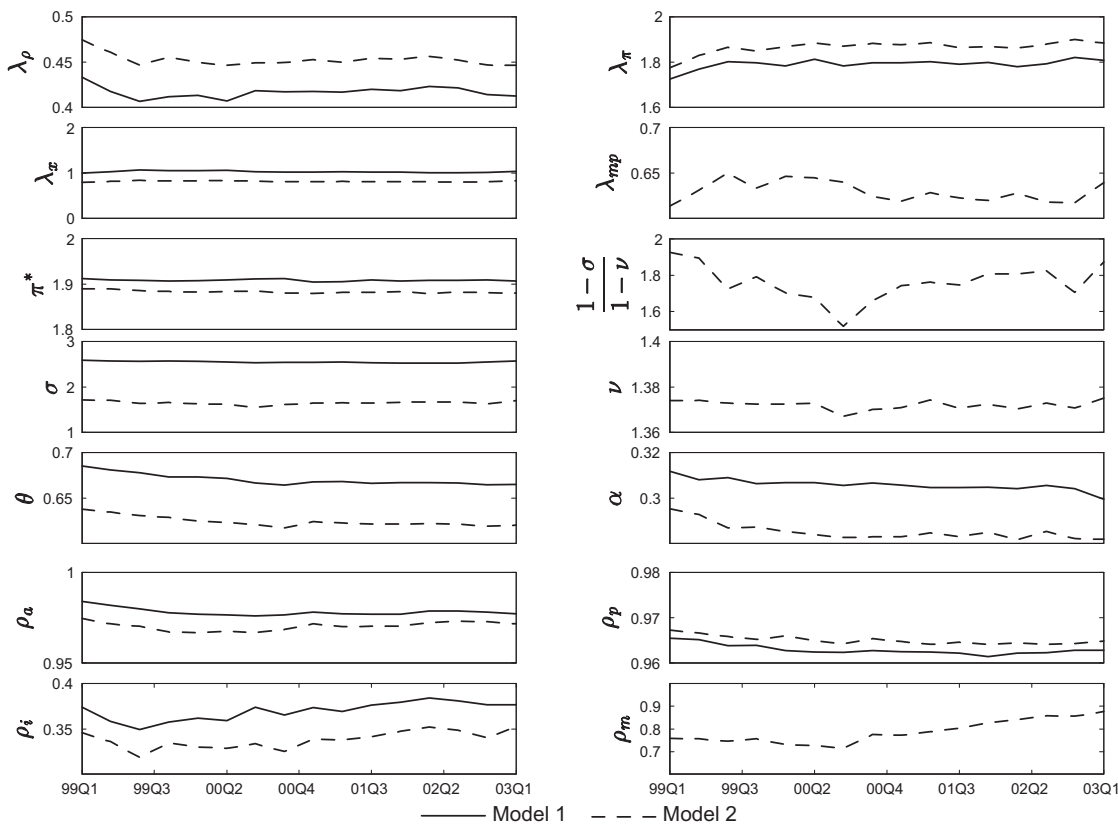

FIGURE C.2. Parameter values for both models during the dot-com crisis. 

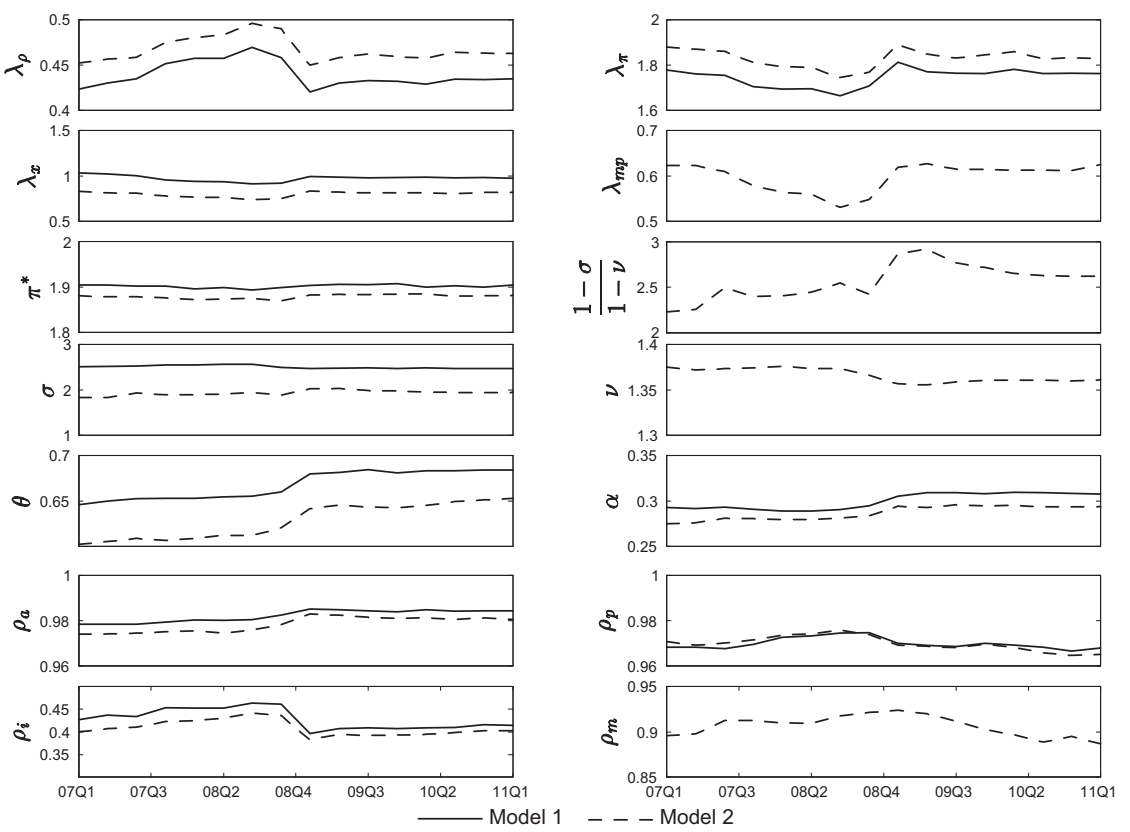

FIGURE C.3. Parameter values for both models during the GFC. 